\title{
Parametric Investigation of Combustion and Heat Transfer Characteristics of Oscillating Linear Engine Alternator
}

\author{
Mehar Bade (D), ${ }^{1}$ Nigel N. Clark $\left(\mathbb{D},{ }^{1}\right.$ Matthew C. Robinson, ${ }^{1}$ and Parviz Famouri ${ }^{2}$ \\ ${ }^{1}$ Department of Mechanical and Aerospace Engineering, West Virginia University, Morgantown, WV, USA \\ ${ }^{2}$ Lane Department of Computer Science \& Electrical Engineering, West Virginia University, Morgantown, WV, USA \\ Correspondence should be addressed to Nigel N. Clark; nigel.clark@mail.wvu.edu
}

Received 31 January 2018; Revised 30 April 2018; Accepted 21 May 2018; Published 28 June 2018

Academic Editor: Sotirios Mamalis

Copyright (c) 2018 Mehar Bade et al. This is an open access article distributed under the Creative Commons Attribution License, which permits unrestricted use, distribution, and reproduction in any medium, provided the original work is properly cited.

\begin{abstract}
An Oscillating Linear Engine Alternator (OLEA) has the potential to overcome the thermal, mechanical, and combustion inadequacies encountered by the conventional slider-crank engines. The linear engines convert the reciprocating piston motion into electricity, thereby eliminating needless crankshaft linkages and rotational motion. As the dead center positions are not explicitly identified unlike crankshaft engines, the linear engine exhibits different stroke and compression ratio every cycle and should manage the unfavorable events like misfire, rapid load changes, and overfueling without the energy storage of a flywheel. Further, the apparatus control and management strategy is difficult for OLEA when compared to conventional engines and depends on the combustion event influencing the translator dynamics. In this research paper, the MATLAB ${ }^{\circledR} /$ Simulink numerical model of a single cylinder, mechanical spring assisted, 2-stroke natural gas fueled, spark-ignited OLEA was investigated to enhance the perception of the coupled system. The effect of combustion and heat transfer characteristics on translator dynamics and performance of OLEA were analyzed by using Wiebe form factors, combustion duration, and heat transfer correlations. Variation in the Wiebe form factors revealed interesting insights into the translator dynamics and in-cylinder thermodynamics of a coupled system. High translator velocity, acceleration, and higher heat transfer rate were favored by low combustion duration.
\end{abstract}

\section{Introduction}

Tightening exhaust emissions and greenhouse gas regulations place great strain on the engine manufacturers to meet regulatory and consumer demands. Further, the limited resources of fossil fuels and rising energy prices necessitate the investigation of highly efficient alternative engine technology [1]. Considering these setbacks, the most desirable engine should be highly productive, durable, inexpensive, and socially acceptable, while marginal improvements like sophisticated control, increased compression ratio, variable valve compression, and high-pressure fuel injection are available. These cutting-edge technologies may not characterize the level of improvement required to sustain the range of demands. Even though many researchers believe that hybrid electric vehicles are a satisfactory solution to the problem, they still depend upon the power density and reliability of conventional crankshaft engine technology [2].
In the interest of engine efficiency, fuel flexibility, cost, and complexity, it is advisable to go for a new technology that can fulfill power and consumer demands. An Oscillating Linear Engine Alternator (OLEA), which converts the reciprocating motion of the piston to electricity, is considered as a viable alternative to fulfill power and consumer demands. The motion of the translator rod is decided merely by the forces acting on it [3]. Furthermore, the OLEA operates only on a few moving parts, that is, translator rod and mechanical springs. The elimination of crankshaft linkages in the design allows unrestricted piston motion, thereby exhibiting different stroke and variable compression ratio every cycle $[4,5]$.

The reasons for the rapid pace and growing interest in the OLEA investigations among the engine research community are stated below:

(i) Structural simplicity: the mechanical linkages to restrict the piston motion in the conventional slidercrank engines are eliminated in the design of OLEA, 
thereby reducing the number of moving parts and complexity in the design

(ii) Low frictional losses: the reduction in the number of moving parts in OLEA design lessens the frictional losses in the device. Furthermore, the ideal OLEA design has no piston side forces induced by the slidercrank mechanism. A greater percentage of the frictional losses is attributed to piston ring frictional losses [6]

(iii) Fuel flexibility: a wide variety of alternative fuels is used for combustion in OLEA with minor hardware alterations [3]

(iv) High thermal efficiency: relative to the slider-crank engine, the OLEA has higher thermal efficiency and higher power density due to reduced weight. Furthermore, the short residence of the piston at the Top Dead Center (TDC) and a faster expansion stroke are beneficial for reducing heat transfer losses, thereby improving the thermal efficiency [7]

(v) Minimal vibration: elimination of crankshaft mechanical linkages reduces the associated forces and moments in the OLEA system, thereby cutting back the vibrations in the OLEA system when compared to crankshaft engine. However, of all the OLEA configurations, the opposed piston configuration with equal piston masses enjoys the benefits of minimal vibrations, whereas single cylinder OLEA is more prone to the vibrations $[5,7]$. The vibrations of the dual cylinder configuration lie in between the single cylinder and opposed piston configuration. However, for the single piston and dual piston OLEA configurations, balancing issues due to mounting the engine need to be addressed

Though OLEA technology is considered as a viable option to replace the crankshaft technology, there are certain challenges associated with this technology:

(i) Starting: the OLEA cannot be cranked just like conventional crankshaft engines and requires special methods for startup. Most OLEA devices are started by running the alternator as a motor until desired compression ratio is reached [5]

(ii) Misfiring: due to the absence of flywheel, the rapid load changes and misfires will affect the translator dynamics for the upcoming stroke and eventually result in the stopping of the engine [8]

(iii) Device control: as the OLEA exhibits cycle to cycle variability, the mistiming of fuel injection and ignition results in the development of unfavorable events like misfires and stalls [7]

Grounded on the above-mentioned plusses and minuses of OLEA, a number of investigations of both single and dual cylinder types have been published [3, 5, 7-9]. In the present investigation, single cylinder design assisted by mechanical springs is investigated using numerical simulation.

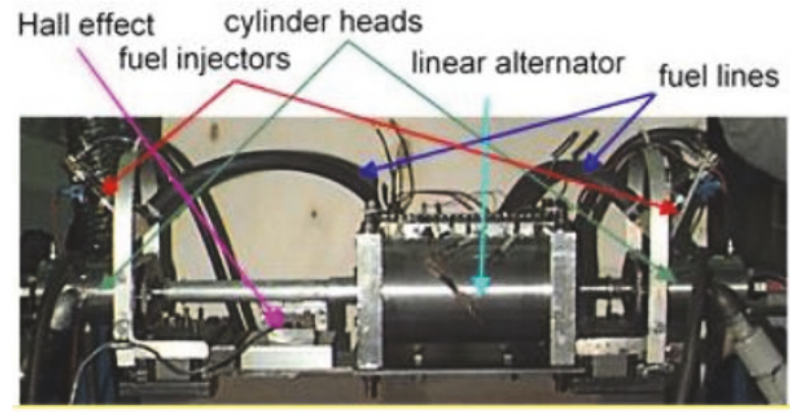

FIGURE 1: Illustration of experimental rig of free piston engine at WVU in 1998 [14].

\section{Reported OLEA Prototypes}

The idea of the development of free piston engines is originally credited to Pescara who started his work in 1922 and developed the first Pescara compressor based on SI combustion in 1925 and the second Pescara compressor based on CI combustion in 1928 [10, 11]. For an extensive understanding on the development of OLEA technology in the $20^{\text {th }}$ century, Aichlmayr compiled a complete timeline of events [12].

In 1995, Callahan et al. from the University of Texas evaluated the scope of free piston engine as a supplementary power source for a hybrid electric vehicle with different engine and alternator configurations [13]. As per their findings, an improvement in the efficiency was observed for the tailored alternator generator based on the translator velocity profile. In 1998, Nigel Clark et al. from West Virginia University (WVU) published two research papers involving fundamental analysis of a linear engine and experimental verification. The first paper described the modeling of translator dynamics using Newton's second law with instantaneous heat rejection and addition using an Otto cycle [5]. The final second-order differential equation was solved to analyze the piston motion and velocity, revealing important insights into the translator dynamics. The illustration of the successful prototype developed by WVU research group in 1998 is shown in Figure 1.

The second publication describes the prototype model built from off-the-shelf components and operated on twostroke, Spark Ignition combustion cycle permitted for a maximum compression ratio of 8:1. A useful power output of 316 $\mathrm{W}$ was developed through stable operation of the engine [14].

At the same time, Van Blarigan et al. from Sandia National Laboratories (SNL) investigated the usage of Homogeneous Charge Compression Ignition (HCCI) with an extensive range of fuels for different stoichiometric ratios and initial temperatures [15]. The significant performance improvement was observed in HCCI case. Following the same line of research, HCCI combustion for hydrogen fuel was modeled using a single zone chemical kinetics [16]. Iterative simulations showed rapid HCCI combustion with improvement in thermal efficiency and reduction in $\mathrm{NO}_{\mathrm{x}}$ emissions when compared to conventional crankshaft engines.

In the year 2000, a German company, FEV Engine Technology, explored several auxiliary power sources for 
hybrid powertrains and identified that the OLEA engines are a viable option to substitute for fuel cells with reference to cost and efficiency [17]. In 2002, Shoukry from WVU worked on the concept of four-stroke OLEA by building a detailed model. The comprehensive model analyzed the importance of stoichiometric ratio, friction, translator mass, geometry of the system, and injection timing with respect to engine frequency and thermal efficiency [18]. In 2002, Van Blarigan from SNL research team developed a loop-scavenged system in KIVA software and aimed at the optimization of scavenging parameters for maximized performance [19].

In the year 2003, the Australian company Pempek Systems Pty. Ltd. presented their third prototype engine generator FP3. Their publications reported a $25 \mathrm{~kW}$ free piston system with 50\% thermal efficiency and 93\% alternator conversion efficiency. Furthermore, their design includes special gas exchange passages unlike conventional port design [20].

Starting in 2007, Mikalsen and Roskilly from New Castle University published an article depicting a broad review of the history, development, and the applications of free piston engine generator [21]. In the year 2009, the same group from Newcastle University developed a Computational Fluid Dynamics (CFD) model to calculate the engine out exhaust emissions from the linear device and assessed them with an equally scaled diesel engine. In the year 2010, they presented their work in regulating the piston motion using feed-forward prediction of the Top Dead Center position in order to govern the fuel flow $[22,23]$.

Toyota is currently developing a single cylinder, $10 \mathrm{~kW}$, gas spring assisted, opposed piston engine as an auxiliary power source in a hybrid electric vehicle. The accompanying publications reported by Toyota are presented here as supplemental information [9, 24]. Another LEA has been constructed by Tatarnikov et al. from Moscow Polytechnic University and has produced $16.87 \mathrm{~kW}$ [25].

Beginning in 2014, researchers at WVU began a new examination aimed at the development of high frequency, spring assisted prototype used as a Combined Heat and Power (CHP) generator at home level [26]. The working prototype is based on a two-stroke, natural gas fueled, spark-ignited single cylinder engine assisted with mechanical springs. The illustration of the prototype under development at WVU is shown in Figure 2.

Most of the OLEA prototypes mentioned here employ a two-stroke thermodynamic cycle. In 2002, Van Blarigan from SNL research team developed a loop-scavenged system in KIVA software and aimed at the optimization of scavenging parameters for maximized performance [19]. Different options were analyzed and compared for loop, hybrid-loop, and uniflow scavenging methods with different delivery options. The CFD results indicated that the uniflow scavenging geometry with low intake pressure attains best engine efficiency and emission characteristics [27]. In 2011, Mao et al. discussed the scavenging performance of the free piston engine by varying engine effective stroke, valve timing, and intake pressure. Their simulation findings suggested that higher trapping and scavenging efficiencies were obtained for a combination of low bore to stroke aspect ratio engine

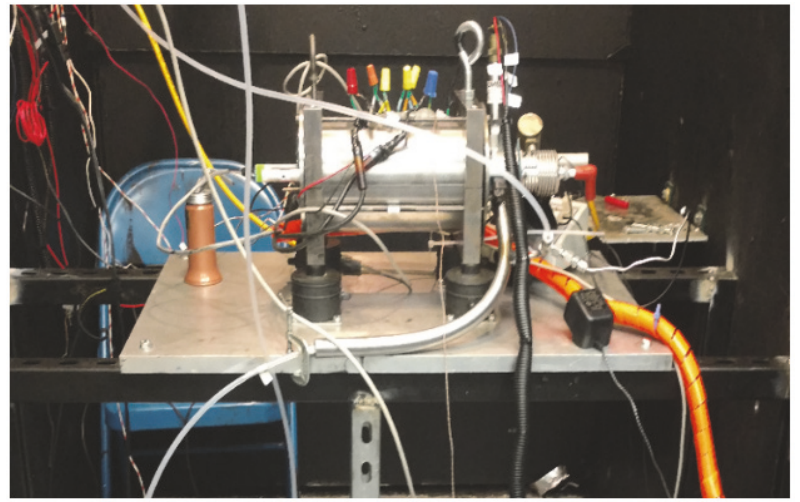

FIGURE 2: Illustration of experimental rig of OLEA at WVU.

with low intake pressure and long valve overlapping timing [28].

In this investigation, the gas exchange process is achieved by using scavenging and exhaust ports [29]. The scavenging process is employed by opening and closing of scavenging port, whereas exhaust blowdown process is achieved by using opening and closing of the exhaust port. These scavenging and exhaust ports are opened and closed according to the location of translator position. The location and the geometric dimensions of these ports are provided as an input to the numerical model. The mass flow rates for the scavenging and exhaust gas process are modeled by using perfect gas mixing model based on pressure differential method [26] and their respective intake and exhaust enthalpies are provided in the numerical model section of this paper. The inefficiencies due to scavenging gas exchange process are categorized into fuel energy losses. Although there exist slight variations in these losses for the concepts presented in this paper, they are not significant enough when compared to other losses in the engine.

\section{Fundamental Physics-Based Model}

Similar to the fundamental analysis of the dual cylinder system [8], the basic model with simplified assumptions is used to analyze the single cylinder linear engine system. The schematic diagram of the single cylinder Oscillating Linear Engine Alternator (OLEA) under study is shown in Figure 3.

An Oscillating Linear Engine Alternator (OLEA) in Figure 3 consists of four major components: internal combustion engine, linear electric machine, translator rod, and mechanical springs. It works on the principle of converting the linear piston motion to electricity by using a centrally mounted linear electric machine. Further, the translator rod and springs are the only moving parts in the system and the motion of the translator rod is decided merely by the summation of forces acting on it. Let $\mathrm{L}_{\mathrm{c}}$ represent the length from alternator housing midpoint to the cylinder head, whereas $L_{p}$ represents the length from alternator housing midpoint to the engine piston crown [8]. Assuming that the translator rod moved the distance $\mathrm{x}$ towards left, at any time 


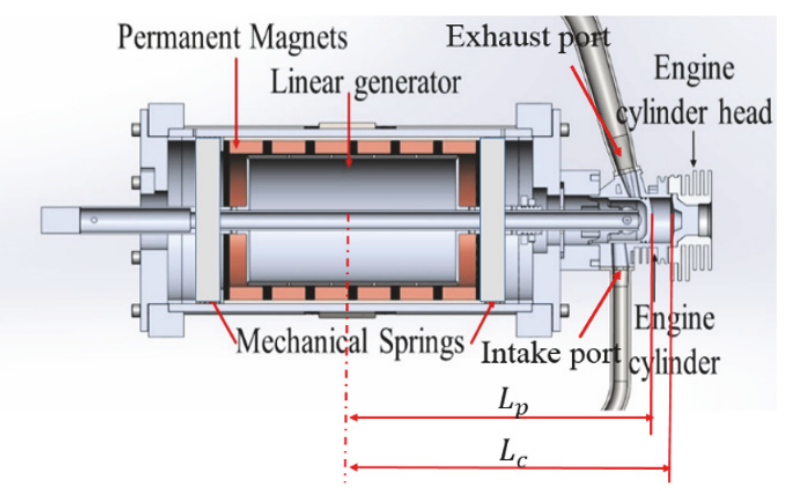

FIgURE 3: Schematic diagram of OLEA.

instance, the instantaneous engine cylinder volume $\left(V_{c y l}\right)$ can be found out using geometrical parameters defined above.

$$
\begin{aligned}
L & =L_{c}-L_{p} \\
V_{c y l} & =\frac{\pi b^{2}}{4}(L+x)
\end{aligned}
$$

Assuming that the pressure in the engine cylinder is $\mathrm{P}_{\mathrm{mp}}$ when the translator zero matches the alternator housing midpoint (i.e., $\mathrm{x}=0$ ) and by modeling the expansion and compression, using polytropic equation yields in-cylinder pressure and cylinder pressure forces as shown in the following equations:

$$
\begin{aligned}
& P_{c y l, i}=P_{m p}\left\{\frac{L}{L+x}\right\}^{\gamma} \\
& F_{c y l, i}=\frac{\pi b^{2}}{4} P_{m p}\left\{\frac{L}{L+x}\right\}^{\gamma}
\end{aligned}
$$

In (3) and (4), the subscripts mp and cyl represent midpoint and cylinder, whereas the terms $\gamma, \mathrm{b}$, and $\mathrm{x}$ denote specific heat ratio, cylinder bore, and translator displacement, respectively.

Similarly, the spring force is provided by the following relationship:

$$
\begin{aligned}
& F_{s p r, l}=k\left(L_{f l}-\left(x+L_{p}\right)\right) \\
& F_{s p r, r}=k\left(L_{f l}+\left(x-L_{p}\right)\right)
\end{aligned}
$$

In (5), the subscripts $1, r$, spr, and fl represent left and right relative to the midpoint of alternator housing, springs, and free length of the springs, whereas $k$ denotes springs stiffness. For basic understanding of the system, the engine follows the Otto Combustion cycle. The following assumptions are incorporated to the fundamental model owing to the complexity:

(i) Addition and rejection of heat take place instantaneously at top and Bottom Dead Centers.

(ii) Cylinder gases are presumed to undergo polytropic compression and expansion. (iii) Work output is merely characterized as a spatially dependent profile that is influenced by the translator rod dynamics.

While the instantaneous heat addition and heat rejection are only for the basic understanding of translator dynamics, the numerical model in the upcoming section considers a more detailed version of heat addition and heat rejection. Higher translator velocity, in-cylinder pressure, and system efficiency are favored by the assumption of instantaneous heat addition.

With the assumptions mentioned above, when the piston reverses its direction at the Top Dead Center (TDC) of engine cylinder, constant volume heat addition occurs. By using the first law of thermodynamics for a closed system and ideal gas equation, the heat addition is shown in the following equations:

$$
\begin{aligned}
& Q_{i n}=m_{c y l g a s} C_{v}\left(T_{c y l, f}-T_{c y l, i}\right) \\
& Q_{i n}=m_{c y l g a s} C_{v}\left(\frac{P_{c y l, f} * V_{c y l, f}}{m_{c y l g a s} * R_{c y l g a s}}-\frac{P_{c y l, i} * V_{c y l, i}}{m_{c y l g a s} * R_{c y l g a s}}\right) \\
& Q_{i n}=\frac{C_{v} V_{c y l, i}}{R_{c y l g a s}}\left(P_{c y l, f}-P_{c y l, i}\right)
\end{aligned}
$$

In (6) and (7), the terms $Q_{i n}, m_{c y l g a s}, C_{v}, \mathrm{P}, \mathrm{V}, \mathrm{T}$, and $\mathrm{R}$ denote heat energy input, mass of cylinder contents, specific heat at constant volume, pressure, volume, temperature, and gas constant, respectively. Since the heat addition occurs at constant volume, the initial and final volumes are equal.

$$
V_{c y l, i}=V_{c y l, f}=\frac{\pi b^{2}}{4}\left(L+x_{r}\right)
$$

where $x_{r}$ represents the distance translator that moved to reach the Top Dead Center of the engine cylinder.

Substituting (8) into (7) and reorganizing for final pressure yield the following equation:

$$
P_{c y l, f}=\frac{4 Q_{\text {in }}}{\pi b^{2}}\left(\frac{\gamma-1}{L+x_{r}}\right)+\left(P_{m p}\left\{\frac{L}{L+x}\right\}^{\gamma}\right)
$$

By using polytropic relationships and the in-cylinder pressure at Top Dead Center, the pressure in the in-cylinder for any translator position and cylinder pressure force are given in the following equations:

$$
\begin{aligned}
& P_{c y l, f} V_{c y l, f}^{\gamma}=P_{c y l} V_{c y l}^{\gamma} \\
& P_{c y l} \\
& \quad=\left(\frac{4 Q_{i n}}{\pi b^{2}}\left(\frac{\gamma-1}{L+x_{r}}\right)+\left(P_{m p}\left\{\frac{L}{L+x}\right\}^{\gamma}\right)\right)\left(\frac{L+x_{r}}{L+x}\right)^{\gamma} \\
& F_{c y l}=\frac{Q_{i n}(\gamma-1)\left(L+x_{r}\right)^{\gamma-1}}{(L+x)^{\gamma}}+\frac{\pi b^{2}}{4} P_{m p}\left\{\frac{L}{L+x}\right\}^{\gamma}
\end{aligned}
$$

By using Newton's second law of motion, the second-order differential equation for force balance is written as follows:

$$
F_{c y l}-F_{s p r}-F_{w}=m \ddot{x}
$$


The term $F_{w}$ includes both friction work and useful alternator work output. The simple compression and expansion spring force $F_{s p r}$ are comprised of both left and right spring force. The equations for $F_{s p r}$ and $F_{w}$ are presented as follows:

$$
\begin{gathered}
F_{w}=F_{a l t}+F_{f r i c} \\
F_{s p r}=F_{s p r, r}-F_{s p r, l}
\end{gathered}
$$

The frictional force includes piston ring frictional force and viscous damping force. The piston ring frictional force is assumed as a function of pressure differential above and below the ring. The corresponding equation for the frictional force is provided as follows:

$$
F_{f r i c}=c_{f} \dot{x}+c_{f}\left(F_{r g}+\pi T_{r g} b\left(P_{c y l}-P_{r g}\right)\right)
$$

The terms $P_{r g}, F_{r g}, T_{r g}, \mathrm{~b}$, and $\dot{x}$ represent pressure below the piston ring, piston ring stiffness force, axial thickness of piston ring, engine cylinder bore, and translator rod velocity, respectively. The friction coefficient $c_{f}$ is calculated based on Blair's relationship depending on engine operation and geometry.

$$
C_{f}=\frac{1}{2} C V_{s w}(60 f)
$$

The terms $\mathrm{C}, V_{s w}$, and $f$ characterize leading coefficient, swept volume, and average engine frequency in $\mathrm{Hz}$. The leading coefficient in the present investigation is assumed as 0.06 based on the research findings of German Aerospace Center (DLR) [30].

The alternator work output is assumed as spatial profile that depends upon the translator rod velocity. Aichlmayr in his dissertation proposed standard alternator work profiles for a free piston linear engine [12]. The work profile of the following form is selected for the present investigation.

$$
F_{a l t}=A \cos \left(\frac{\pi x}{2 L}\right)
$$

The work amplitude $(\mathrm{A})$ is calculated by matching the engine output with the alternator load. Combining all the equations and substituting them in (12) yield (17). The second-order differential equation for the force balance (17) is solved to obtain a closed-form solution for translator dynamics (i.e., relations between translator position, velocity, and acceleration). The changes in the combustion parameters are explained in a detailed manner in Numerical Model Description.

$$
\begin{aligned}
& \frac{Q_{i n}(\gamma-1)\left(L+x_{r}\right)^{\gamma-1}}{(L+x)^{\gamma}}+\frac{\pi b^{2}}{4} P_{m p}\left\{\frac{L}{L+x}\right\}^{\gamma} \\
& -2 k x-c_{f} \dot{x}-c_{f}\left(F_{r g}+\pi T_{r g} B\left(P_{c y l}-P_{r g}\right)\right) \\
& -A \cos \left(\frac{\pi x}{2 L}\right)=m \ddot{x}=m \dot{x} \frac{d \dot{x}}{d x}
\end{aligned}
$$

\section{Numerical Model Description}

The interpretation of management and control of OLEA depends upon the sophisticated numerical simulations.
Although there are multiple approaches for modeling a single submodel, the total time needed to simulate multiple cycles of operation is not feasible owing to high-speed computing and costs associated. For example, one can model the frictional characteristics of piston rings in different ways. One possible approach is to employ the use of iteration-based Reynolds hydrodynamic equation applied across multiple zones around piston rings. However, this method is computationally expensive and time-consuming. To overcome the hindrances, many researchers simply assume the frictional forces as a function of piston velocity and pressure differential between in-cylinder and interring pressure. Similarly, substantial effort has been made to incorporate a robust and sophisticated combustion model without restricting the attempt of extreme computational needs.

Even though the fundamental-physics-based model offers valuable perception into the operation and behavior of OLEA, more realistic simulation includes highly sophisticated heat addition, heat rejection, and alternator models. Since closed-form solutions are unlikely to exist for more detailed modeling, MATLAB/Simulink timebased model was developed to understand the behavioral characteristics of linear engine.

Just as in the physics-based model presented above, Newton's second law of motion is used to define translator dynamics. To accommodate more accurate heat addition and heat transfer in the numerical analysis, the in-cylinder pressure is expressed by a first-order differential pressure equation that is shown as follows:

$$
\begin{aligned}
\frac{d P}{d t} & \\
= & \frac{-P \gamma}{V} \frac{d V}{d t} \\
& +\left(\frac{\gamma-1}{V}\right)\left(\frac{d Q_{H R}}{d t}-\frac{d Q_{H T}}{d t}+\frac{d H_{\text {in }}}{d t}-\frac{d H_{\text {out }}}{d t}\right)
\end{aligned}
$$

The terms $\mathrm{P}, \mathrm{V}, \gamma, \mathrm{Q}_{H R}, \mathrm{Q}_{H T}, H_{\text {in }}, H_{\text {out }}$, and $t$ represent pressure, volume, ratio of specific heats, heat released due to combustion, heat transfer between the cylinder walls and gas, inlet enthalpy, outlet enthalpy, and time, respectively. The inlet and outlet enthalpies depend upon the mass flow rates due to scavenging and exhaust blowdown process, temperatures, and specific heats. The scavenging and exhaust blowdown mass flow rates are calculated using perfect mixing model that is based on the pressure differential [26]. The blow-by losses are also included in the enthalpy losses flowing out of the cylinder.

Compressed Natural Gas (CNG) is selected as a fuel for this investigation. The specific heats at constant pressure and constant volume for all the natural gas constituents are dependent on temperature and are defined according to the tables. The composition of natural gas selected for this investigation is shown in Table 1.

The first-order differential equation for heat transfer from the engine cylinder takes the form shown in (19). The term $T_{w}$ denotes wall temperature and it is assumed that the temperature is the same over the piston crown, 
TABLE 1: Composition of natural gas used in this investigation.

\begin{tabular}{lc}
\hline Component & \% of composition by volume \\
\hline Methane & $90 \%$ \\
\hline Ethane & $9 \%$ \\
\hline Propane & $1 \%$ \\
\hline
\end{tabular}

wall, and cylinder head. The wall temperature in the current investigation is adapted from a slider-crank test rig available at WVU.

$$
\frac{d Q_{H T}}{d t}=h A\left(T-T_{w}\right)
$$

The convective heat transfer coefficient $(h)$ can be evaluated using several empirically associated formulae defined by Hohenberg [31, 32], Woschni [33], and Annand [34]. The correlations presented above are for slider-crank driven engines. Empirical models for variable and unusual motion of linear engine are not available, but the slider-crank models can be adapted with some confidence. For the base case, the Hohenberg heat coefficient formulation was used, while the Woschni and the Annand formulae were employed in the investigation for comparison. A similar comparison was employed by Robinson for dual cylinder and is repeated here for the single cylinder device [35]. Hohenberg's convective heat transfer coefficient relationship with geometrical and operational parameters is provided in the following equation:

$$
h=a V^{b} T^{c} P^{d}\left(V_{p}+1.4\right)^{e}
$$

In (20), $V, T, P$, and $V_{p}$ denote volume in $m^{3}$, temperature in $\mathrm{K}$, pressure in bar, and average piston speed in $\mathrm{m} / \mathrm{s}$, respectively. The terms $a, b, c, d$, and $e$ are empirical constants and their values are $130,-0.06,-0.4,0.8$, and 0.8 in that order.

Heat addition in the combustion chamber depends upon complex pressure wave dynamics, flame front propagation, quenching, preignition, and knock characteristics of working fluid. Linear engine simulations with detailed chemical kinetics cannot give accurate results in reasonable computational times. Further, for a coupled system with multiple subsystems and multicycle modeling, it is not feasible to use detailed chemical kinetics model considering the computational time and costs. To overcome the hindrances in the computational time and costs associated, a time-based empirical Wiebe function model was used for modeling the rate of combustion in the present investigation [36]. Furthermore, the potential for preignition and knock is neglected.

$$
\begin{aligned}
\chi(t) & =1-\exp \left[-a\left(\frac{t-t_{\text {soc }}}{t_{c d}}\right)^{b+1}\right] \\
\frac{d Q_{H R}}{d t} & =\eta_{\text {comb }} H V_{\text {fuel }} \frac{d \chi(t)}{d t}
\end{aligned}
$$

The combustion efficiency $\left(\eta_{\text {comb }}\right)$ is provided as an input variable that is tuned from crankcase test rig. This combustion efficiency of $95 \%$ is realistic for the natural gas and was obtained from the similar size crankcase test rig experiments.
The combustion efficiency is influenced by many factors within the free piston engine system, so modeling $\eta_{\text {comb }}$ is out of this research paper's scope. Further, the variations in the Wiebe form factors and combustion duration are not accompanied by the changes in the combustion efficiency as the effect of combustion efficiency deviation was found to be small based on the crankcase investigation of similar size. The form factors "a" and "b" in the time-dependent Wiebe function are set to 5 and 2, respectively [36]. The term " $t_{c d}$ " denotes the combustion duration that is set to 1 $\mathrm{ms}$ for base case. However, the variations in the combustion duration are examined in the upcoming section of this paper for comparison. The total heat value (HV) of combustion charge relies upon the fuel and equivalence ratio of mixture inside the combustion chamber.

The important variable in a time-based Wiebe function is the prediction of start of combustion (SOC). Since the OLEA system in the current exploration is modeled for Spark Ignition combustion cycle, the start of combustion is predicted by using spark generation signal that acts as a trigger to activate the ignition system. The spark controller signal is generated when the translator rod velocity exceeds a threshold value. The threshold velocity is provided as an input variable to the controller and can be modified to achieve either early ignition or late ignition or optimal ignition according to the experiments. Once the spark is triggered, the combustion occurs according to the Wiebe heat release correlation based on the form factors and combustion duration defined earlier.

The numerical model follows the same model for the frictional losses as explained earlier in the fundamental-physicsbased analysis section. A linear alternator generator designed with permanent magnets is coupled to the translator rod in order to generate electricity from the reciprocating motion caused by the combustion of fuel. An equivalent circuit alternator coil approach is used to define the energy output from the linear alternator. The alternator force comprises both electromagnetic and cogging forces. The electromagnetic force is modeled as a function of translator velocity, whereas the cogging force is the thrust force from the alternator that is needed to overcome the interaction of magnetic fields from permanent magnets. It is provided as an input table obtained from finite element analysis for different translator positions. The relationship for the alternator electromagnetic force is presented in the following equation [37]:

$$
F_{w}=C_{a l t} W_{c} \dot{x}
$$

The term $C_{a l t}$ denotes constant flux change depending on translator rod position. The weight of the controller $\left(W_{c}\right)$ scales the alternator force according to the variation in the compression ratio. If the compression ratio of the engine is increased, higher alternator force is applied, whereas the alternator load is reduced for corresponding reduction in compression ratio. This controller weight forces the OLEA system to operate within certain limits of target compression ratio, thereby ensuring steady-state operation.

The stability of OLEA is determined by governing load equation for translator dynamics in tandem with the management of the combustion events. If more net energy is released 


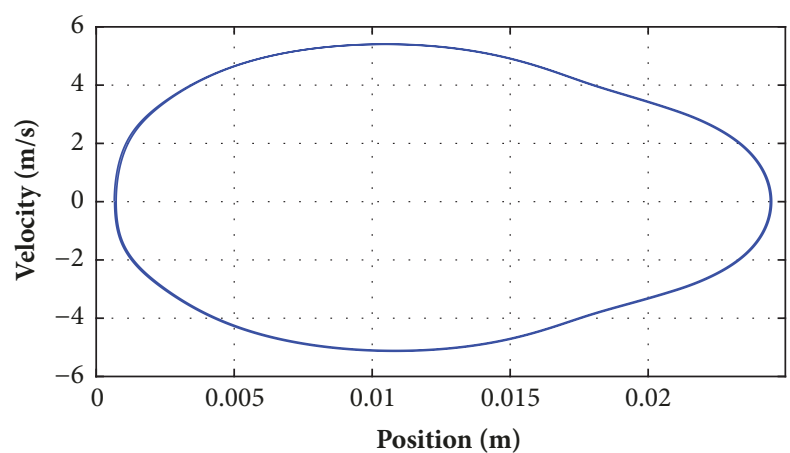

Figure 4: Translator dynamics for base case. The fairly egg shape variation in the translator velocity suggests the domination of combustion forces from single cylinder.

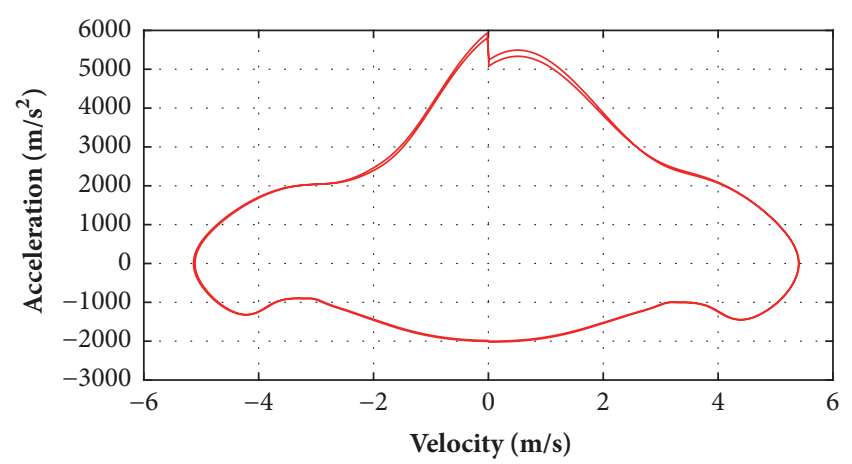

FIgURE 5: Translator dynamics for base case (clockwise). The peak in the acceleration of the translator corresponds to the peak in the in-cylinder pressure due to heat release.

in the course of combustion than is consumed by losses and the alternator, with all else being equal, the engine will achieve higher compression ratio on the subsequent cycle. If this process continues, additional energy will be gained in the system and the translator velocity at mid-stroke will be higher in contrast to prior cycles. This is analogous to the storage of more energy, as higher speed of the reciprocating components and flywheel in a conventional engine, if the delivered power exceeds the applied load.

Similarly, if inadequate fuel is delivered to the engine or if combustion efficiency is poor, the heat released during combustion is reduced and the compression ratio decreases in successive cycles. However, the actual operation, management, and stability of such a variable compression ratio linear engine depend upon the numerous events taking place in the whole alternator-engine-springs system. Optimized control for stable operation of linear engines is a subject warranting more research.

\section{MATLAB/Simulink Model Results}

The modeling results presented in this paper exhibit the change in the operation of OLEA as Wiebe form factors, combustion duration, and heat transfer parameters are modified. To begin with, the simulation results for a base case are presented in Figures 4-9. For the base case, the heat release

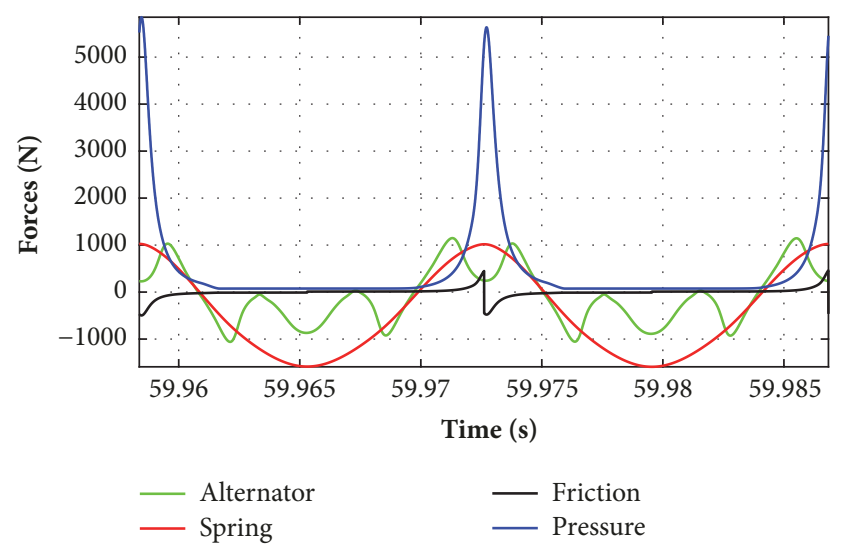

FIGURE 6: The breakdown of forces acting on the translator rod at steady-state operation of OLEA. The term "pressure" represents the in-cylinder pressure forces acting on the translator rod.

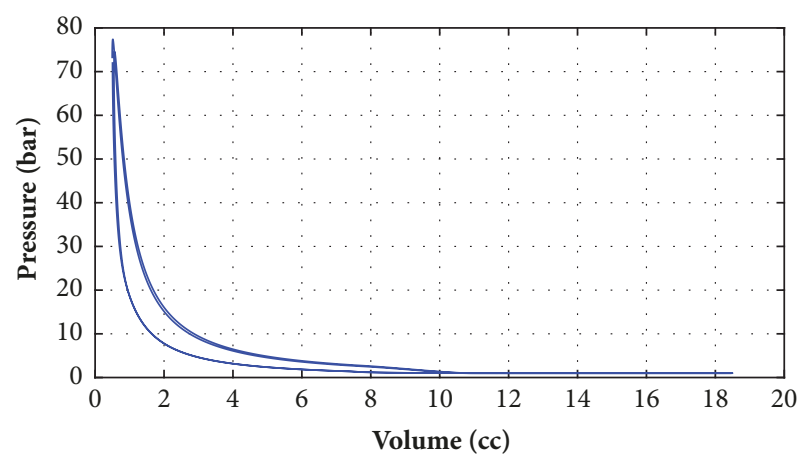

FIGURE 7: Variation of in-cylinder pressure as a function of volume.

and heat transfer were modeled by using time-based Wiebe function and Hohenberg's correlation, respectively. The input and steady-state parameters for base case are listed in Table 2.

Figures 4 and 5 explain the dynamic characteristics of single cylinder linear engine alternator system. Figure 4 represents the variation in the translator rod velocity with respect to translator displacement. The nonsymmetrical characteristic of translator velocity in Figure 4 is due to the dominant effect of in-cylinder combustion forces over the translator dynamic system. Towards the right of velocity profile, the velocities are fairly small due to the absence of combustion forces. The steep nature of the velocity profile at the dead center is an explanation for the short residence of the piston at the dead centers in OLEA. Figure 5 shows the variation in the acceleration with respect to translator velocity. The steep rise in the acceleration at the Top Dead Center is due to the initiation of combustion once the translator velocity exceeds the threshold spark timing velocity.

The various forces acting on the translator rod were plotted against time in Figure 6. The term "pressure" in the legend represents the cylinder pressure forces acting on the translator rod. It is evident that the cylinder combustion forces dominate the next peak forces (i.e., mechanical spring forces) by a factor of 4-5. The odd-looking alternator forces in Figure 6 are due to the juxtaposition of poles. Since the 

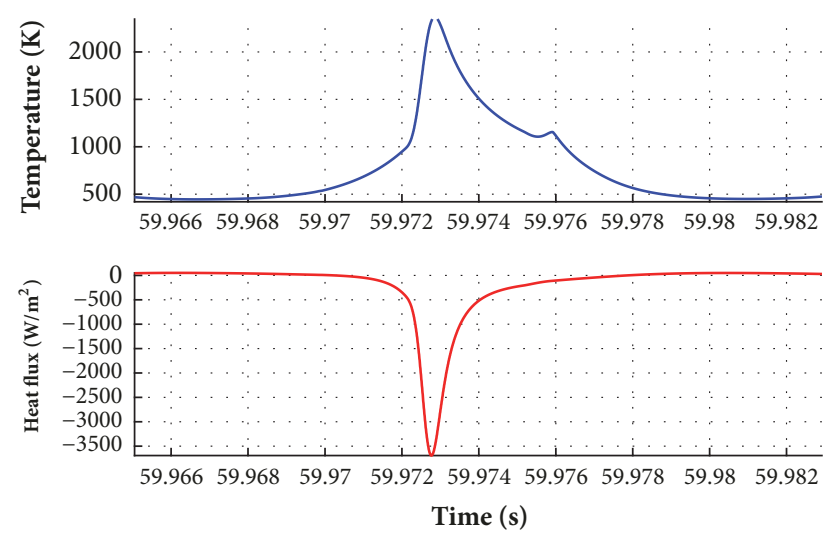

FIgURE 8: Top: variation of in-cylinder temperature against time for one steady-state cycle of operation. Bottom: variation of heat flux modeled using Hohenberg correlation. The secondary peak in the temperature curve denotes the gas exchange process from the exhaust.
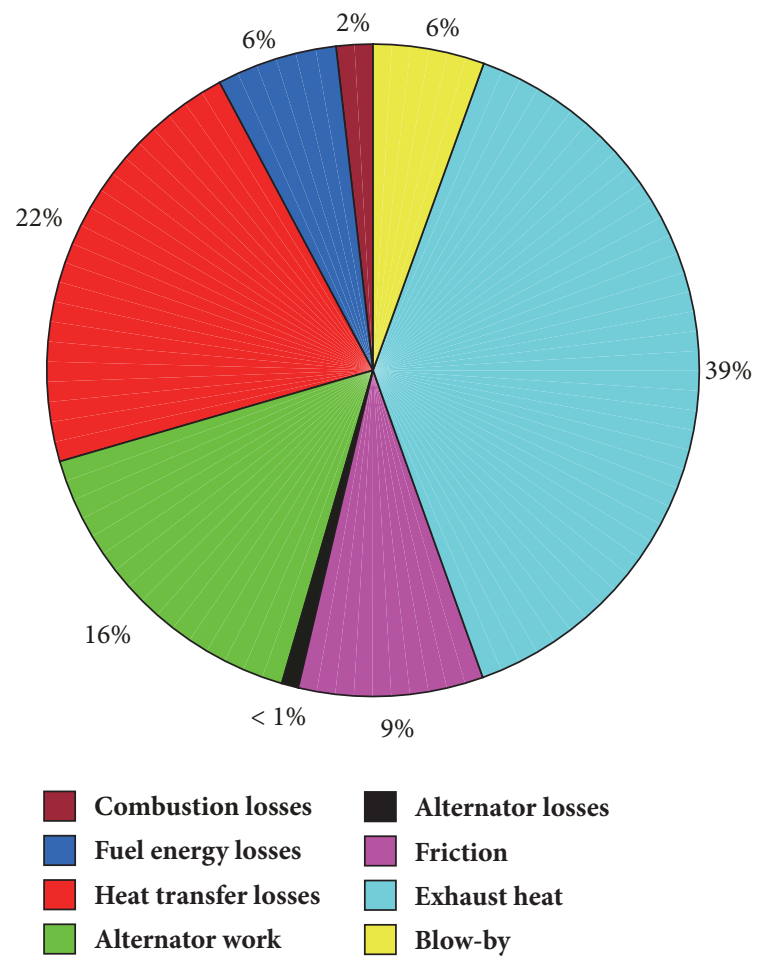

FIGURE 9: Distribution of combustion energy pathways during steady-state operation. Fuel energy losses represent the flow losses due to pressure differential in the intake and exhaust system.

mechanical flexures are considered as simple compressible springs, the spring forces are sinusoidal in nature. The PV diagram for the base case is presented in Figure 7.

To supplement the plots presented above, the variation of heat flux with in-cylinder temperature is shown in Figure 8. A closer look at heat flux in Figure 8 shows that the rapid increase in the heat flux is due to rise in cylinder temperature associated with combustion heat release. The heat transfer
TABLE 2: Input and steady-state parameters for fundamental case linear engine.

\begin{tabular}{lc}
\hline Cylinder bore & $31.02 \mathrm{~mm}$ \\
\hline Maximum cylinder stroke & $24.97 \mathrm{~mm}$ \\
\hline Engine displacement volume & $18.87 \mathrm{cc}$ \\
\hline Equivalence ratio & 1.02 \\
\hline Exhaust port location from head & $88.25 \mathrm{~mm}$ \\
\hline Translator frequency & $49.5 \mathrm{MJ} / \mathrm{kg}$ \\
\hline LHV of natural gas & $300 \mathrm{~K}$ \\
\hline Intake temperature & $100 \mathrm{kPa}$ \\
\hline Intake pressure & $95 \%$ \\
\hline Alternator efficiency & $95 \%$ \\
\hline Combustion efficiency & $77.4 \mathrm{bar}$ \\
\hline Max in-cylinder pressure & $2368 \mathrm{~K}$ \\
\hline Max in-cylinder temperature & 15 \\
\hline Compression ratio & $1.2 \mathrm{~kg}$ \\
\hline Translator mass & $450 \mathrm{~K}$ \\
\hline Wall temperature & $30180 \mathrm{~N} / \mathrm{m}$ \\
\hline Spring stiffness & 6 \\
\hline Number of springs & $16.48 \%$ \\
\hline System efficiency &
\end{tabular}

flux that depends upon the instantaneous area available, incylinder temperature, and cylinder wall temperature falls during the expansion stroke due to increase in the instantaneous area. Further, the temperature that decides the heat transfer also follows the same trend until the commencement of exhaust and recharging process.

Figure 9 shows the breakdown of steady-state OLEA energy balance for a set of operating variables. The overall system efficiency is approximated at $16.48 \%$ with $22 \%$ and $39 \%$ of the input fuel energy lost to in-cylinder heat transfer and exhaust heat, respectively. The cylinder heat transfer being the second major energy loss has significant influence on the translator dynamics and OLEA system efficiency importantly. The fuel energy losses represent the flow losses in the intake system due to pressure differential in the intake and engine cylinder, whereas combustion losses represent the losses related to combustion inefficiency. If the in-cylinder pressure is greater than crankcase pressure, then fuel air mixture flows into the crankcase, which is referred to as blow-by losses. These blow-by losses are calculated based on the pressure differential method after the closure of exhaust and intake ports.

5.1. Variation in Wiebe form Factors. An investigation is carried out to understand the variation in the translator dynamics and performance for different Wiebe form factors while maintaining all other parameters constant [36]. Further, it is of utmost importance to examine various values of form factor in order to get a good match for the experimental in-cylinder pressure traces. The mass fraction of the fuel burned defined by time-based Wiebe function will never reach unity. At a given time equal to combustion duration, the MFB is less than unity by a factor $e^{-a}$. For instance, at time equal to combustion duration, if the value of "a" is assumed as 

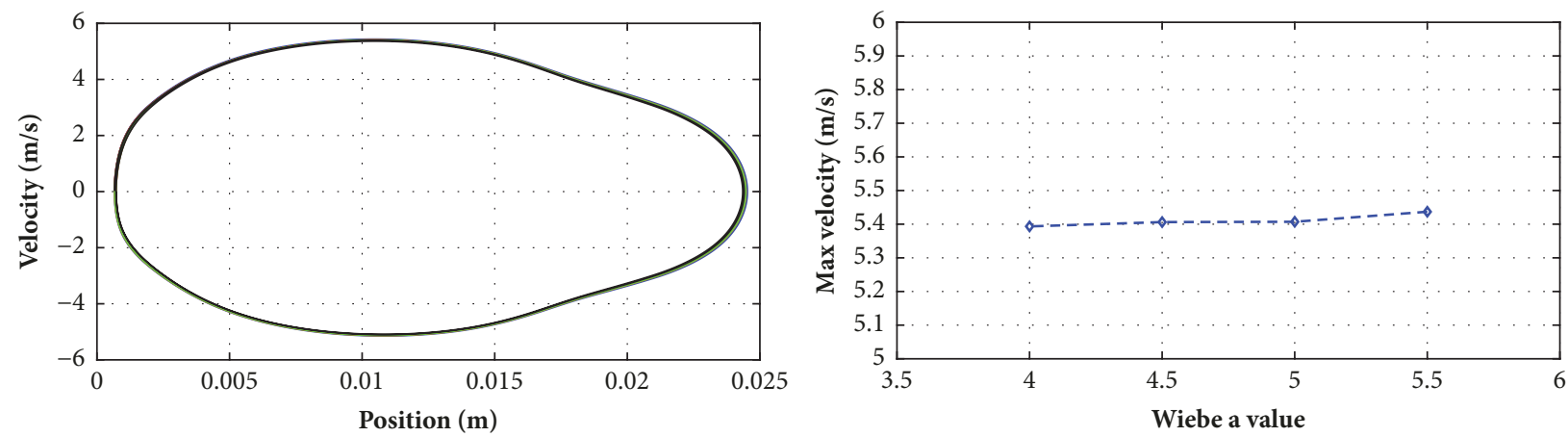

$$
\begin{aligned}
& \mathrm{a}=5.5 \quad-\mathrm{a}=4.5 \\
& \mathrm{a}=5
\end{aligned}
$$

FIGURE 10: Variation in translator velocity with respect to position for different values of Wiebe parameter "a."
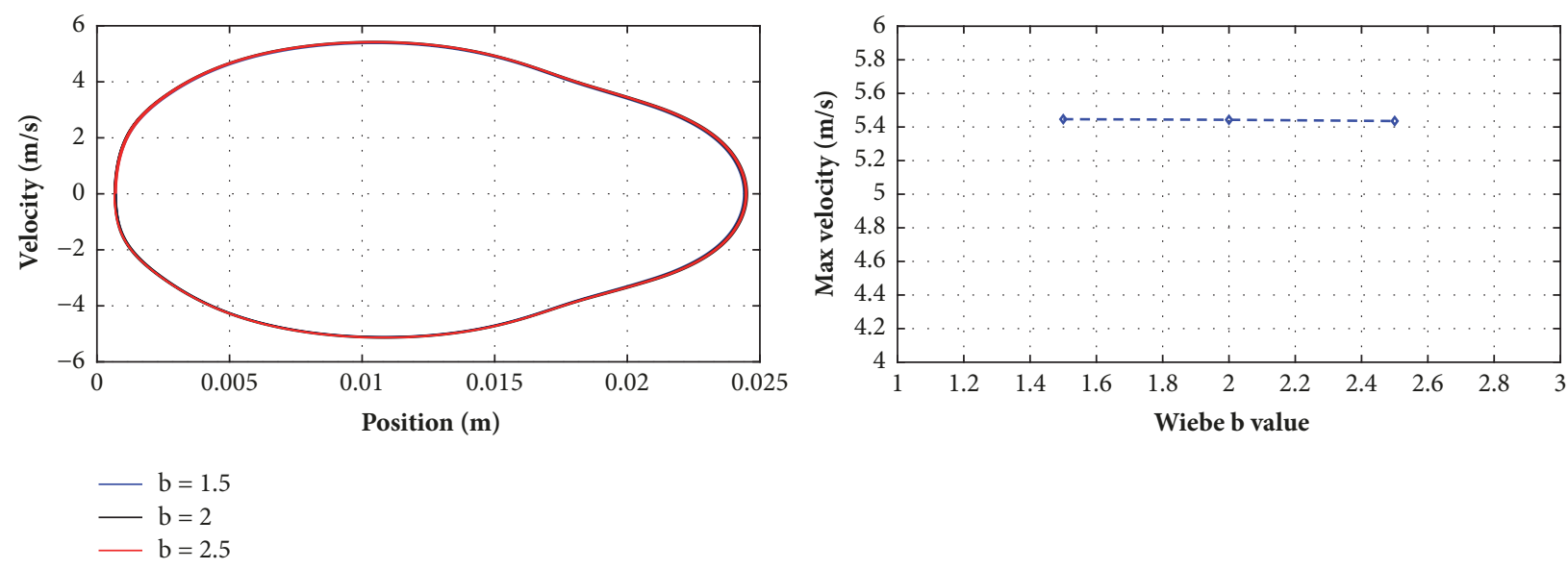

FIGURE 11: Variation in translator velocity with respect to position for different values of Wiebe parameter "b."

5, the amount of MFB corresponds to $0 \%-99.32 \%$; similarly, for $\mathrm{a}=4$, the amount of MFB corresponds to $0 \%-98.16 \%$. The change in the form factor "a" is not accompanied by the change in the combustion efficiency. As the combustion efficiency is prescribed in the model, the changes in the heat release rate are taken care of by using mass fraction burnt. The form factor parametric sweep results provided interesting insights into the translator rod dynamics and performance of OLEA system.

Figures 10-17 show the modeling results for different cases of form factors variation. Figures 10 and 11 represent the variation in the translator velocity profile for form factor "a" variation and form factor " $b$ " variation. Increasing the form factor "a" increased the translator velocity due to increase in the mass fraction burned closer to unity, thereby increasing the in-cylinder pressure forces. On the other hand, an increase in the form factor " $b$ " reduced the translator velocity. This is due to the fact that, at any time step, the mass fraction burnt will be higher for lower form factor "b." It is evident from the mass fraction burned (MFB) profile plot for different values of form factor "b" which is shown in Figure 12. For example, at $150^{\text {th }}$ time step, $63.3 \%$ of mass fraction is burnt for form factor "b" value of $1.5,62.1 \%$ of mass fraction is burnt for value of 2.0 , and $60.2 \%$ of mass fraction is burnt for value of 2.5, respectively. These variations in the MFB caused the variations in the in-cylinder pressures and heat release rate.

As the translator acceleration is obtained from the timebased differentiation of velocity, the translator acceleration also follows the same trend. The variation in the in-cylinder pressure traces for different values of form factors "a" and "b" is shown in Figures 13 and 14. As the mass faction burnt becomes closer to the unity, the heat release input increases with an increase in the form factor, thereby causing the increase in the pressure and in-cylinder temperature. The temperature that decides the heat flux causes the heat flux to follow the same trend and is evident from Figure 15. Similarly, increasing the form factor "b" reduced the value of mass fraction burnt at any time step when compared to lower values of form factor "b." Further, the gradual rise in the MFB burnt at higher form factor "b" reduced the heat release rate, thereby reducing the in-cylinder pressures at higher form factors. The heat flux also follows the same trend and is provided in Figure 16. The major losses in the OLEA system from the parametric sweep studies of Wiebe form factors are presented in Figure 17. The heat transfer losses are increased by increasing the form factor "a" due to high temperatures 


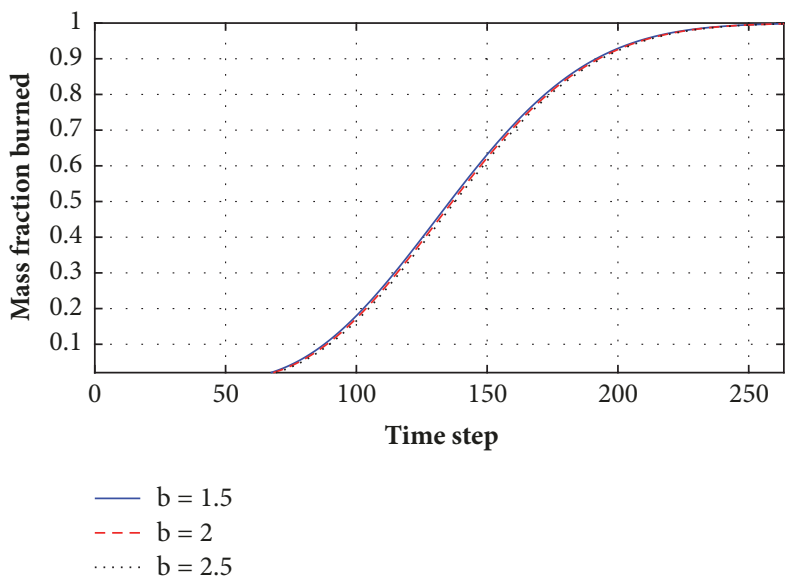

FIGURE 12: Mass fraction burnt profile for different values of Wiebe parameter "b." At any time instant, the mass fraction burnt (MFB) is higher for low value of "b."
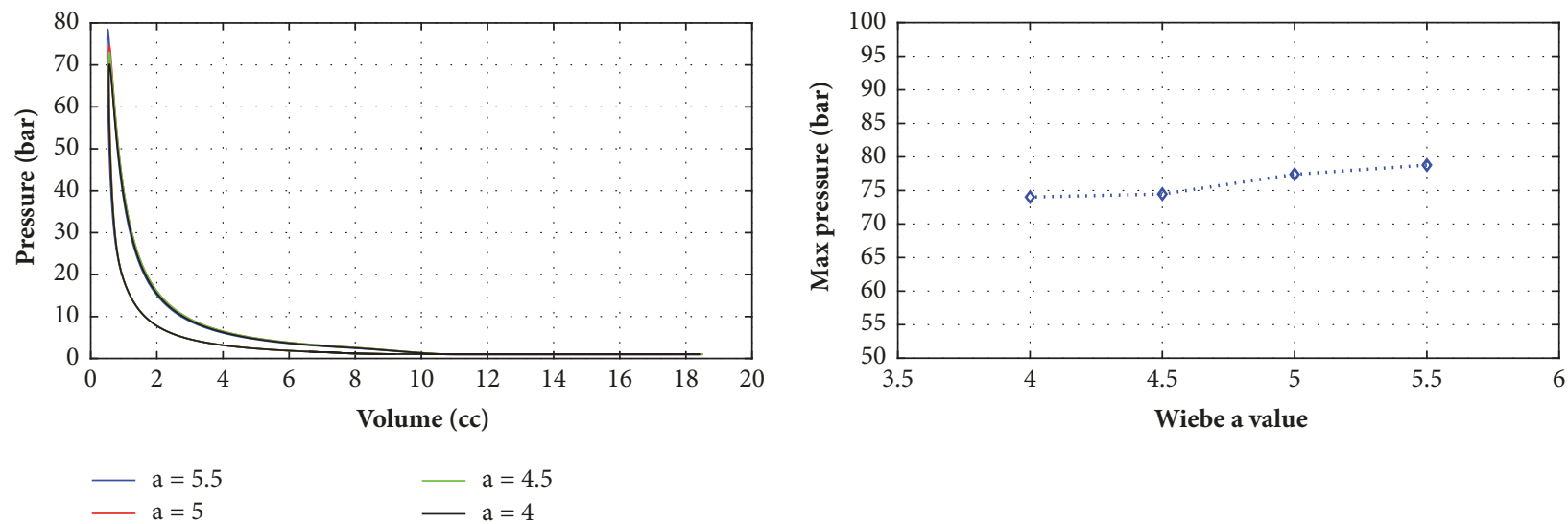

FIGURE 13: Variation in in-cylinder pressure with respect to volume for different values of Wiebe parameter "a." The rise in the pressure with form factor "a" is due to MFB becoming closer to unity for high form factor value.
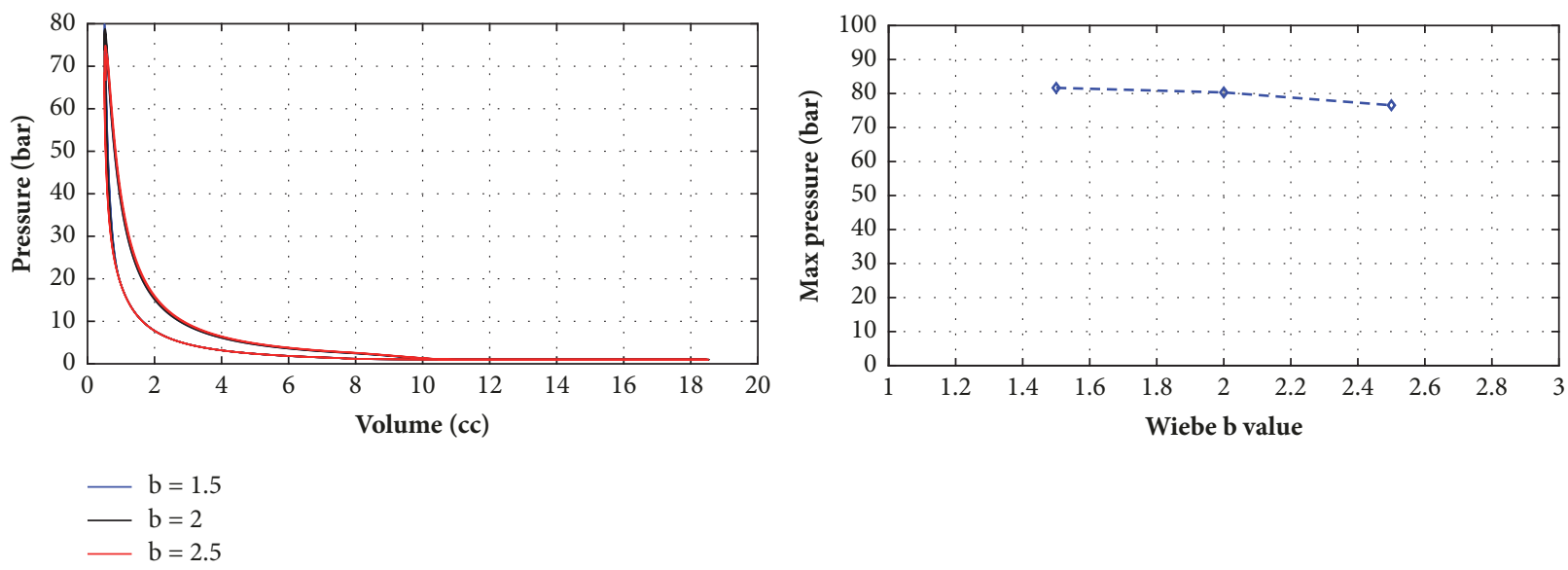

FIGURE 14: Variation in in-cylinder pressure with respect to volume for different values of Wiebe parameter "b." The fall in the pressure with form factor " $b$ " is due to the shape of MFB profile. 

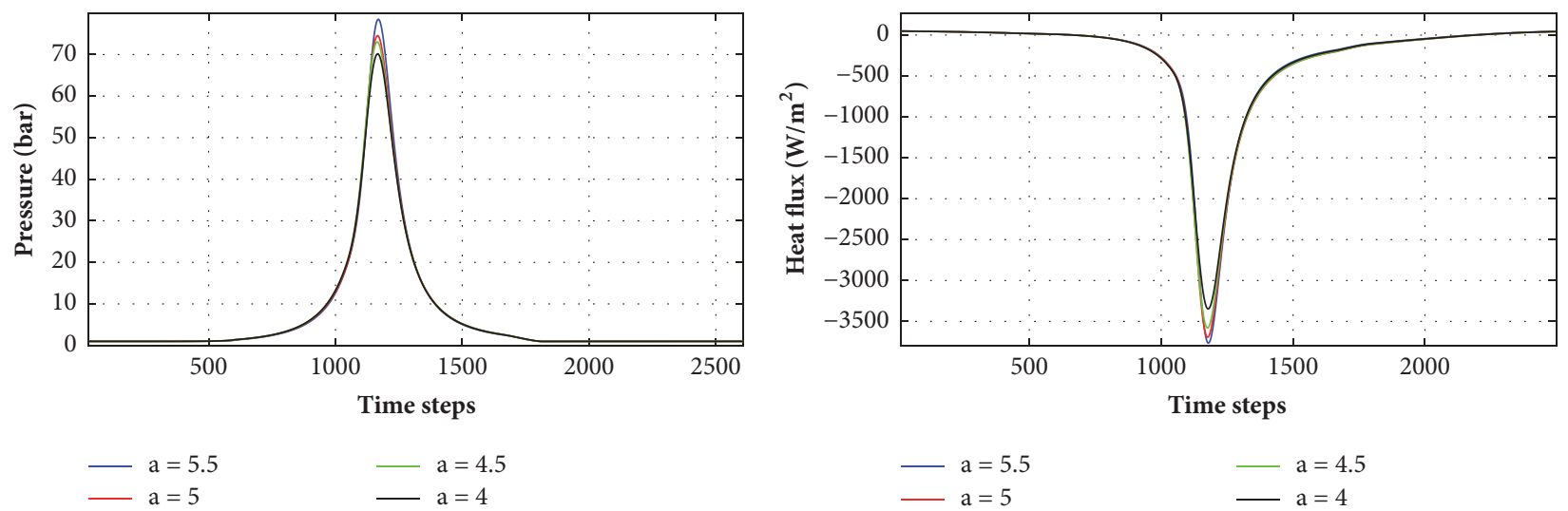

FIGURE 15: In-cylinder pressure traces and heat flux variation with form factor "a." The higher the value of "a," the higher the heat flux due to high in-cylinder temperatures.
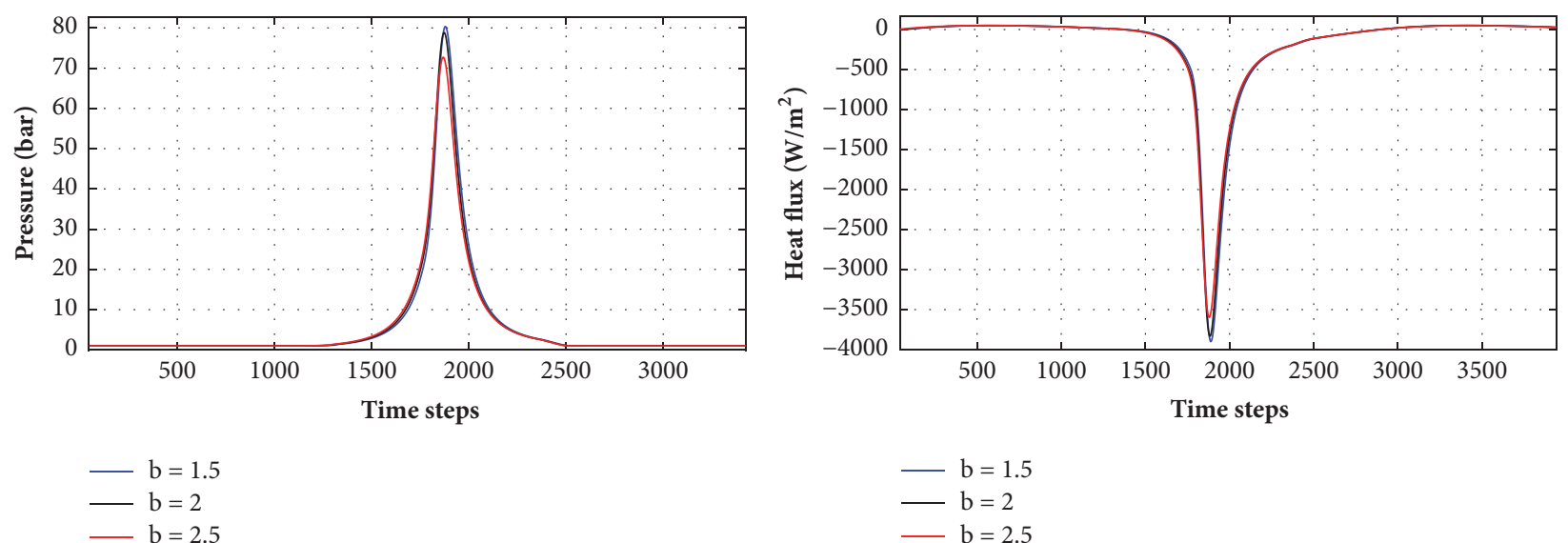

FIGURE 16: In-cylinder pressure traces and heat flux variation with form factor "b."
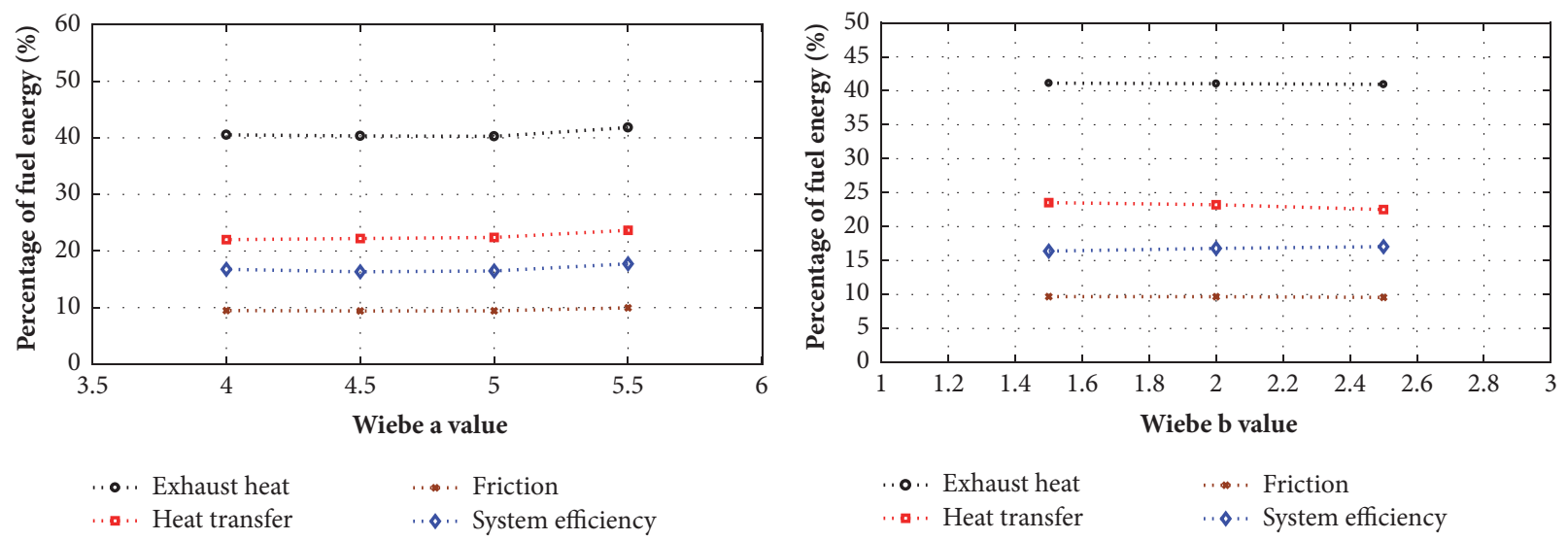

FIGURE 17: Major energy losses comparison for different values of Wiebe form factors.

associated at higher values of "a." Further, a slight increase in the system efficiencies is observed with increasing the Wiebe form factors.

5.2. Variation in Combustion Duration. The combustion characteristics in this investigation are characterized by using
Wiebe form factors and combustion duration. Further, the changes in the combustion duration are not accompanied by the changes in the combustion efficiency. It is presumed that the decrease in the combustion duration causes the immediate heat release, thereby improving system efficiency. Just like steady-state parameters presented in Table 2, many stable 

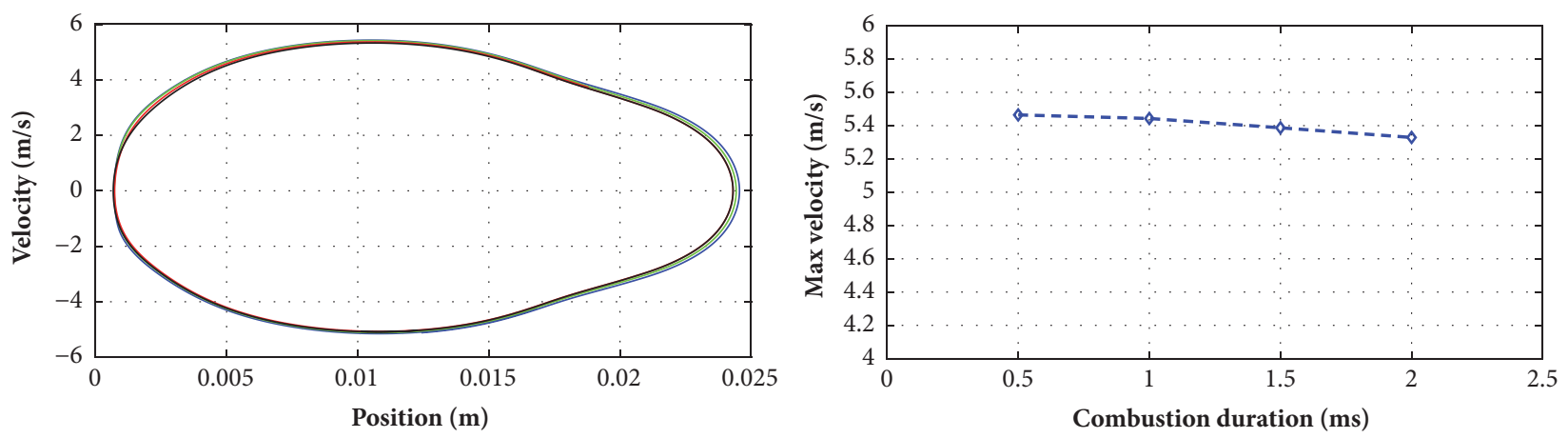

$$
\begin{array}{rlrl}
-\mathrm{t}_{\mathrm{c}} & =0.5 \mathrm{~ms} \\
-\mathrm{t}_{\mathrm{c}} & =1 \mathrm{~ms} & -\mathrm{t}_{\mathrm{c}}=1.5 \mathrm{~ms} \\
-\mathrm{t}_{\mathrm{c}} & =2 \mathrm{~ms}
\end{array}
$$

FIGURE 18: Translator velocity profiles for different combustion durations. Higher velocities are attained at lower combustion duration due to instantaneous in-cylinder forces.
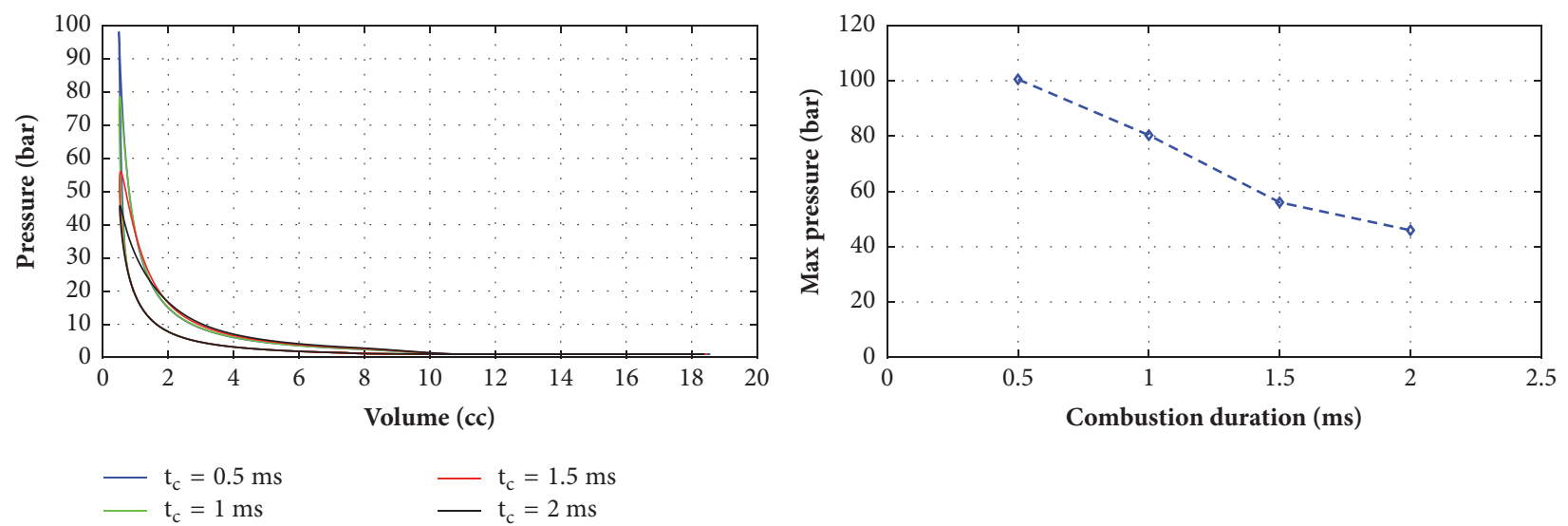

FIGURE 19: In-cylinder pressure traces from the combustion chamber for different combustion duration. Higher pressures are favored by lower combustion due to instantaneous heat addition.

solutions are possible for successful operation of OLEA; one such solution is presented here. Figures 18-22 present the simulation results for different combustion durations.

Figure 18 shows the variation in the velocity profile for different combustion durations. Higher velocities are achieved at lower combustion durations. This is due to the instantaneous heat addition that caused the rapid rise in the pressure at almost constant volume at lower combustion duration. For higher combustion duration, the rise in the heat release rate is gradual rather than instantaneous. With instantaneous heat addition, higher pressures are achieved at lower combustion duration and are evident from Figure 19. Higher translator rod frequencies are observed at lower combustion duration, which is evident from Figure 20.

Similarly, higher temperatures are attained due to reduction in combustion duration causing greater heat transfer rate, which is shown in Figure 21. Figure 22 shows the distribution of major losses of OLEA for different combustion durations. Due to higher in-cylinder temperatures attained for lower combustion duration, the heat transfer losses are higher for low combustion duration. Further, the instantaneous heat addition due to low combustion duration reduced the exhaust thermal energy losses, whereas increasing the combustion duration increased the exhaust thermal energy losses as the exhaust blow down occurred later in the stroke. The frictional losses that are modeled as a function of translator velocity reduced with an increase in the combustion duration. From Figure 22, it is evident that the decrease in the combustion duration increased the overall system efficiency to a certain extent. Reducing the combustion efficiency even further reduced the overall system efficiency due to pronounced effect of heat transfer losses when compared to other losses. At higher combustion duration, the exhaust heat losses are more prominent even though the heat transfer and frictional losses are reduced. This obvious effect of exhaust heat losses reduced the overall system efficiency for higher combustion duration.

5.3. Variation in Heat Transfer Correlation. Figures 23 and 24 show the effect of different heat transfer correlations used to define the heat losses in OLEA system. In these three cases, higher system efficiency and lower heat losses are observed for Hohenberg correlation, while high heat losses and lower efficiency are obtained with Annand correlation. The 


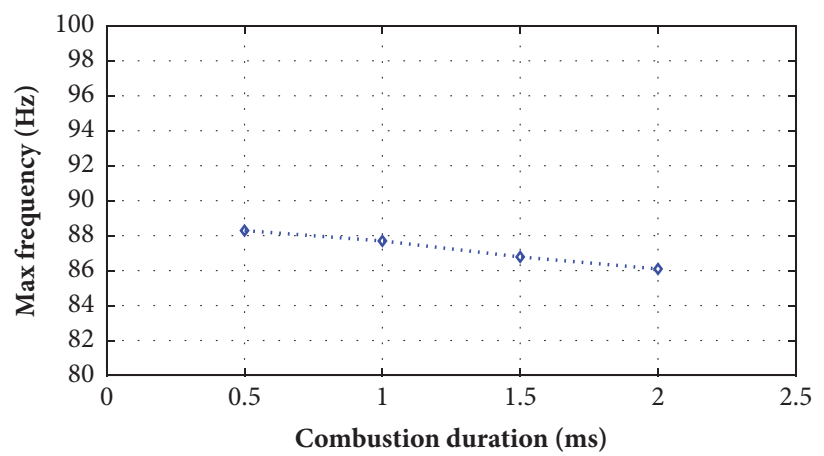

FiguRE 20: Variation in the translator frequency for different combustion durations. The reason for the higher frequencies is the greater dominance of in-cylinder pressure forces at low combustion duration.
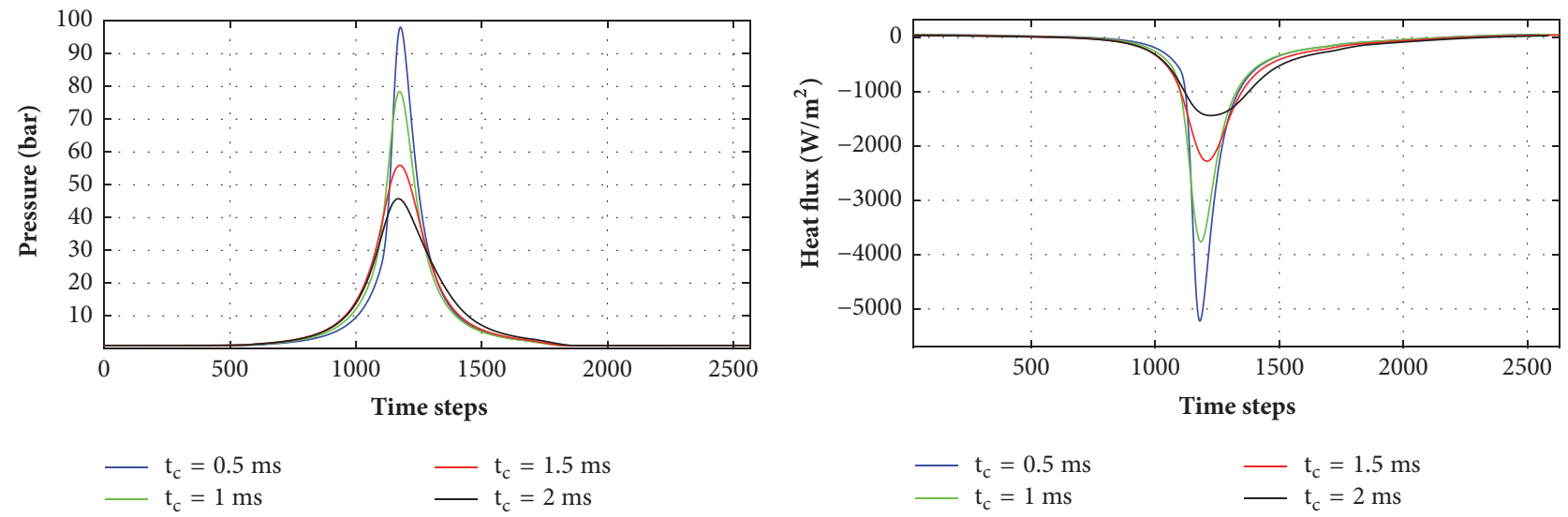

FIGURE 21: Variation of in-cylinder pressures and heat transfer flux for different combustion durations. Higher heat flux is attained due to rapid rise in the cylinder temperature for low duration of combustion.

difference in the heat losses is associated with thermodynamic relationships, dissimilarities in in-cylinder pressure domain, and subtle variations in translator dynamics.

\section{Summary/Conclusions}

The Oscillating Linear Engine Alternator (OLEA) has been investigated relentlessly for few decades owing to the benefits offered by it over conventional crankshaft engines. To augment the understanding of OLEA operation and management, the fundamental physics-based model has been described. With the assistance of well-built numerical simulation, a parametric exploration has been carried out to study the effect of combustion and heat transfer characteristics on the translator dynamics and performance of OLEA.

The combustion characteristics are characterized by using Wiebe form factors and combustion duration. Increase in the form factor "a" increased the mass fraction burned closer to unity, which further increased the translator velocity, cylinder pressure, temperature, and heat transfer rate. On the same note, low value of form factor " $b$ " resulted in the maximum amount of mass fraction burned at any time step when compared to higher values of " $b$ " and thereby exhibited sharp rise in the pressure and heat transfer rate. Further, a slight increase in the system efficiencies is observed with increasing the Wiebe form factors.

Combustion duration had a strong effect on the translator dynamics, in-cylinder pressure, and OLEA behavior. High translator velocity, high acceleration, and rise in maximum combustion chamber pressure were favored by low combustion duration. The decrease in the combustion duration increased the system efficiency to a certain extent. Reducing the combustion efficiency even further reduced the system efficiency due to pronounced effect of heat transfer losses when compared to other losses. At higher combustion duration, the exhaust heat losses are more prominent even though the heat transfer and frictional losses are reduced. This obvious effect of exhaust heat losses reduced the system efficiency for higher combustion duration.

Variation in the heat transfer calculations was modeled by using Hohenberg, Woschni, and Annand's correlations. Moderate variations in heat transfer, in-cylinder pressure, and gas temperature were observed as all the correlations are dependent upon the combustion heat release that is further dependent upon the combustion timing and duration.

Although there exists only one correct MFB curve that represents the experimental in-cylinder pressure traces for a specific spring stiffness, it is of utmost importance to examine 

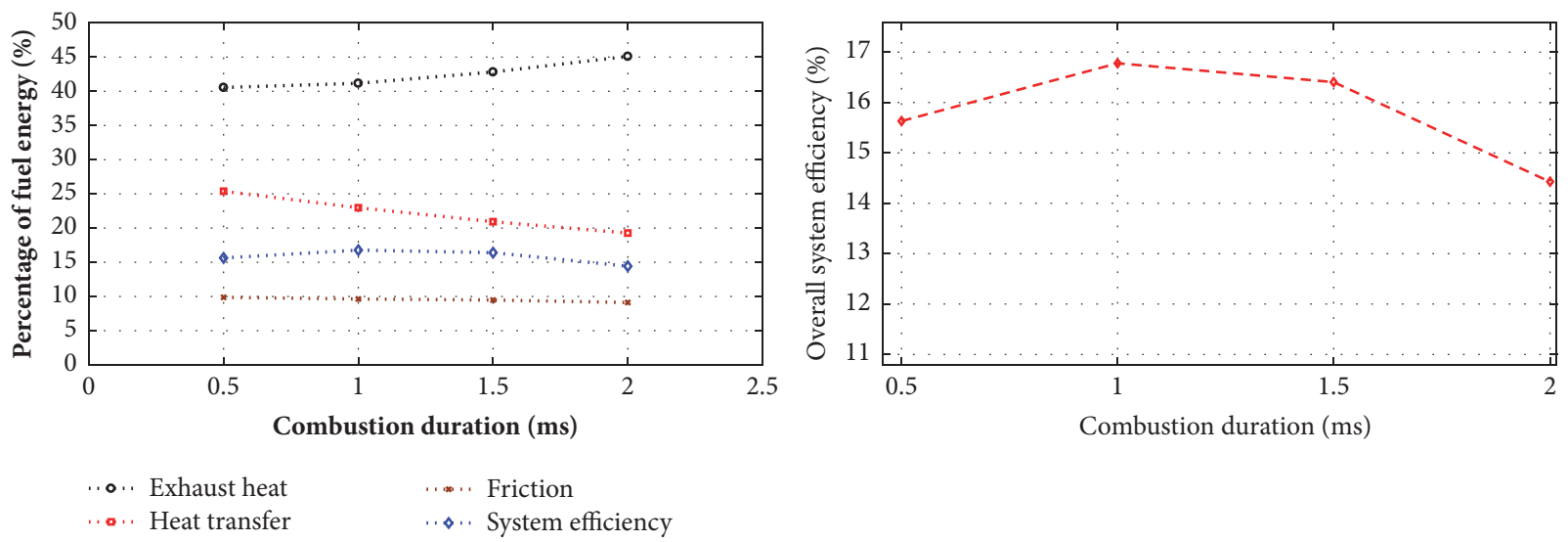

FIGURE 22: Major energy losses comparison for different combustion duration. Heat transfer and frictional losses decreased with increase in combustion duration, while exhaust heat increased with an increase in combustion duration.

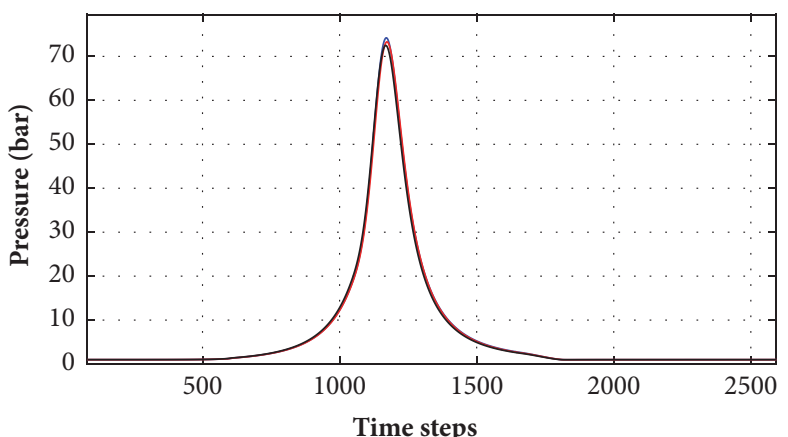

- Hohenberg

Woschni

Annand

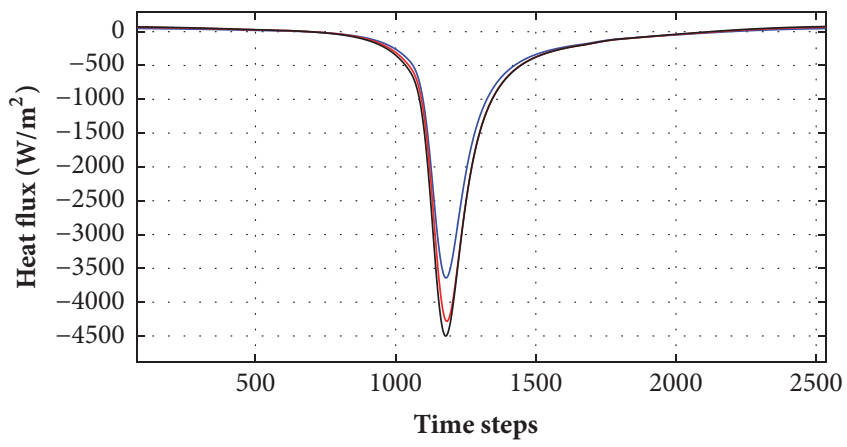

Hohenberg
Woschni

FigURE 23: Variation in pressure and heat flux for different heat transfer correlations.

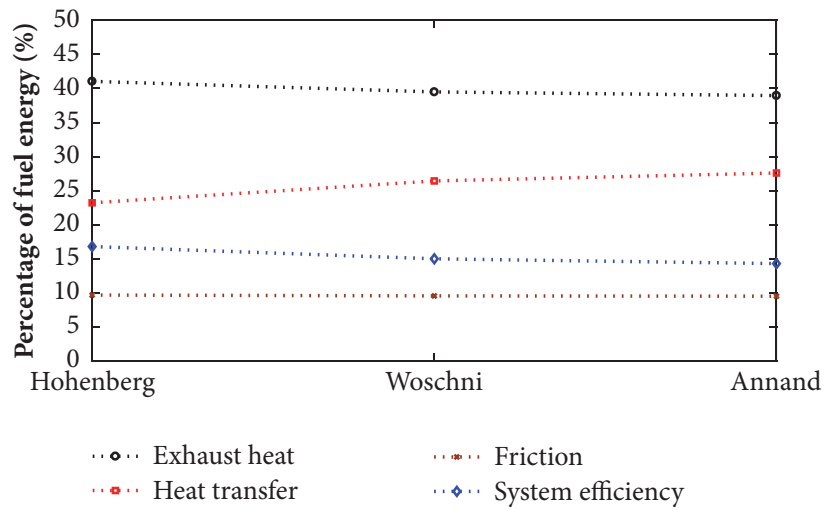

FIGURE 24: Distribution of major losses in OLEA system for different heat transfer correlations. Lower heat loss and higher efficiency are observed for Hohenberg correlation.

various values of form factor in order to get a good match for the experimental traces. Further, if the spring stiffness of the specially designed mechanical flexures is varied, the incylinder pressure traces will vary, and the results obtained from this study will be useful for matching the in-cylinder pressure curves. Even without the access to the experimental data at this moment, it is believed that this investigation will add some value for those who are investigating the higher frequency OLEA system running at frequencies above $80 \mathrm{~Hz}$ which are not yet explored by many researchers. 


\section{Future Research Scope}

The utmost and useful direction in understanding the operation and strategic control of OLEA is the experimental validation of data obtained from numerical simulation. This is the main motto of linear engine researchers at West Virginia University. The combustion and heat transfer information will be collected from OLEA test rig and it is used for studying the deviations and discrepancies in the conventional slidercrank-based empirical models used in modeling. Finally, the superiority of the heat transfer and combustion study stemming from this investigation will be improved by developing more robust, realistic, and sophisticated numerical model.

\section{Appendix}

See Figures 4-24.

\section{Abbreviations}

OLEA: Oscillating Linear Engine Alternator

SI: $\quad$ Spark gnition

CI: Compression gnition

WVU: West Virginia University

SNL: Sandia National Laboratories

HCCI: Homogeneous Charge Compression Ignition

CFD: Computational Fluid Dynamics

CHP: Combined Heat and Power

TDC: Top ead enter

BDC: Bottom ead enter

DLR: German Aerospace Center

MFB: Mass raction of fuel urned

LHV: Lower Heating.

\section{Data Availability}

The data used to support the findings of this study are available from the corresponding author upon request.

\section{Conflicts of Interest}

The authors declare that there are no conflicts of interest regarding the publication of this paper.

\section{Acknowledgments}

This research was conducted under West Virginia University's Oscillating Linear Engine Alternator (OLEA) project. It was funded by DOE ARPA-E GENSETS program to the West Virginia University (DE-AR0000608). The authors gratefully acknowledge the support of DOE ARPA-E for funding this work. The authors also acknowledge the support and funding from the WVU George B. Berry chair endowment.

\section{References}

[1] V. Etacheri, R. Marom, R. Elazari, G. Salitra, and D. Aurbach, "Challenges in the development of advanced Li-ion batteries: a review," Energy \& Environmental Science, vol. 4, no. 9, pp. 32433262, 2011.
[2] F. Kock, J. Haag, and H. E. Friedrich, "The free piston linear generator - Development of an innovative, compact, highly efficient range-extender module," SAE Technical Papers, vol. 2, 2013.

[3] N. B. Hung and O. Lim, "A review of free-piston linear engines," Applied Energy, vol. 178, pp. 78-97, 2016.

[4] S. S. Goldsborough and P. Van Blarigan, "A numerical study of a free piston IC engine operating on homogeneous charge compression ignition combustion," SAE Technical Papers, 1999.

[5] C. Tóth-Nagy, Linear engine development for series hybrid electric vehicles, West Virginia University, 2004.

[6] Y. Woo, Y. Lee, and Y. Lee, “The performance characteristics of a hydrogen-fuelled free piston internal combustion engine and linear generator system," International Journal of Low-Carbon Technologies, vol. 4, no. 1, pp. 36-41, 2009.

[7] R. Mikalsen and A. P. Roskilly, "A review of free-piston engine history and applications," Applied Thermal Engineering, vol. 27, no. 14-15, pp. 2339-2352, 2007.

[8] C. Robinson Matthew, Analysis and Optimization of a Dual Free Piston, Spring Assisted, Linear Engine Generator, West Virginia University, 2015.

[9] C. Yuan, J. Xu, and H. Feng, "In-cylinder heat transfer and gas motion of a free-piston diesel engine generator," Proceedings of the Institution of Mechanical Engineers, Part A: Journal of Power and Energy, vol. 231, no. 8, pp. 739-752, 2017.

[10] P. R. Pateras, Motor-Compressor Apparatus, U.S. Patent 1,657, 641, January 31, 1928.

[11] H. O. Farmer, "Free-Piston Compressor-Engines," Proceedings of the Institution of Mechanical Engineers, vol. 156, no. 1, pp. 253271, 2006.

[12] H. T. Aichlmayr, Design considerations, modeling, and analysis of micro-homogeneous charge compression ignition combustion free-piston engin, University of Minnesota, 2002.

[13] T. J. Callahan and K. S. Ingram, "Free-piston engine linear generator for hybrid vehicles modeling study," Interim report, January-August 1994 AD-A-294318/1/XAB; TFLRF305, Southwest Research Inst. Belvoir Fuels and Lubricants Research Facility (1995), San Antonio, TX, USA, 1994.

[14] W. R. Cawthorne, P. Famouri, J. Chen et al., "Development of a linear alternator-engine for hybrid electric vehicle applications," IEEE Transactions on Vehicular Technology, vol. 48, no. 6, pp. 1797-1802, 1999.

[15] P. Van Blarigan, N. Paradiso, and S. Goldsborough, "Homogeneous charge compression ignition with a free piston: A new approach to ideal otto cycle performance," SAE Technical Papers, 1998.

[16] S. S. Goldsborough and P. Van Blarigan, "Optimizing the scavenging system for a two-stroke cycle, free piston engine for high efficiency and low emissions: A computational approach," SAE Technical Papers, 2003.

[17] M. Goertz and L. Peng, "Free piston engine its application and optimization," SAE Technical Papers, 2000.

[18] E. Shoukry, S. Taylor, N. Clark, and P. Famouri, Numerical simulation for parametric study of a two-stroke compression ignition direct injection linear engine, West Virginia University, 2003.

[19] P. Van Blarigan, "Advanced internal combustion electrical generator," in Proceedings of the 2002 DOE Hydrogen Program Review, National Renewable Energy Laboratory, Golden, CO, May 2002. 
[20] D. Carter and E. Wechner, "The Free Piston Power Pack: Sustainable power for hybrid electric vehicles," SAE Technical Papers, no. 2003-01-327, 2003.

[21] S. Petreanu, Conceptual analysis of a four-stroke linear engine, West Virginia University, 2002.

[22] R. Mikalsen and A. P. Roskilly, "A computational study of freepiston diesel engine combustion," Applied Energy, vol. 86, no. 7-8, pp. 1136-1143, 2009.

[23] R. Mikalsen, E. Jones, and A. P. Roskilly, "Predictive piston motion control in a free-piston internal combustion engine," Applied Energy, vol. 87, no. 5, pp. 1722-1728, 2010.

[24] H. Kosaka, T. Akita, K. Moriya et al., "Development of free piston engine linear generator system part 1 - Investigation of fundamental characteristics," SAE Technical Papers, vol. 1, no. 2014-01-1203, 2014.

[25] A. Tatarnikov, L. Lezhnev, N. Khripach, D. Petrichenko, F. Shustrov, and V. Ivanov, "Two-stroke direct fuel inject free piston generator from theory to practice," Journal of Engineering and Applied Sciences, vol. 23, pp. 13486-13496, 2016.

[26] M. C. Robinson and N. N. Clark, "Study on the Use of Springs in a Dual Free Piston Engine Alternator," SAE Technical Papers, no. 2016-01-2233, 2016.

[27] S. S. Goldsborough and P. Van Blarigan, "Optimizing the scavenging system for a two-stroke cycle, free piston engine for high efficiency and low emissions: A computational approach," SAE Technical Papers, no. 2003-01-0001, 2003.

[28] J. Mao, Z. Zuo, W. Li, and H. Feng, "Multi-dimensional scavenging analysis of a free-piston linear alternator based on numerical simulation," Applied Energy, vol. 88, no. 4, pp. 1140-1152, 2011.

[29] B. Jia, Y. Wang, A. Smallbone, and A. Roskilly, "Analysis of the Scavenging Process of a Two-Stroke Free-Piston Engine Based on the Selection of Scavenging Ports or Valves," Energies, vol. 11, no. 2, p. 324, 2018.

[30] S. Schneider, F. Rinderknecht, and H. E. Friedrich, "Design of future concepts and variants of the Free Piston Linear Generator," in Proceedings of the 2014 9th International Conference on Ecological Vehicles and Renewable Energies, EVER 2014, 8, 1 pages, mco, March 2014.

[31] G. F. Hohenberg, "Advanced approaches for heat transfer calculations," SAE Technical Papers, no. 790825, 1979.

[32] B. Jia, Z. Zuo, H. Feng, G. Tian, and A. P. Roskilly, "Development Approach of a Spark-Ignited Free-Piston Engine Generator," SAE Technical Papers, no. 2014-01-2894, 2014.

[33] G. Woschni, "A universally applicable equation for the instantaneous heat transfer coefficient in the internal combustion engine," SAE Technical Papers, no. 670931, 1967.

[34] W. J. D. Annand, "Heat transfer in the cylinders of reciprocating internal combustion engines," Proceedings of the Institution of Mechanical Engineers, vol. 177, no. 1, pp. 973-996, 1963.

[35] M. C. Robinson and N. N. Clark, "Effect of Combustion Timing and Heat Loss on Spring-Assisted Linear Engine Translator Motion," SAE International Journal of Engines, vol. 9, no. 1, pp. 546-564, 2016.

[36] I. Wiebe, Halbempirische Formel für die Verbrennung-Geschwindigkeit, Verlag de Akademic der Wissenschaften der VdSSR, 1956.

[37] H. Feng, Y. Song, Z. Zuo, J. Shang, Y. Wang, and A. P. Roskilly, "Stable operation and electricity generating characteristics of a single-cylinder free piston engine linear generator: Simulation and experiments," Energies, vol. 8, no. 2, pp. 765-785, 2015. 


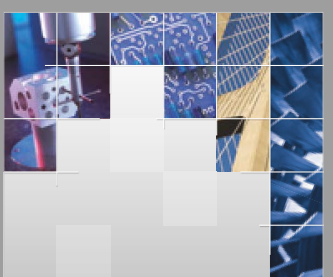

\section{Enfincering}
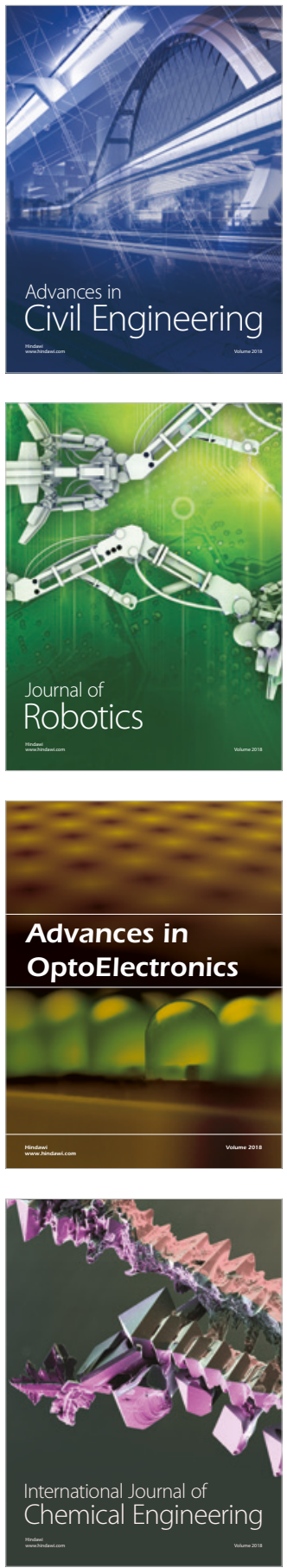

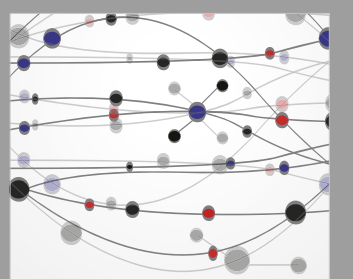

\section{Rotating \\ Machinery}

The Scientific World Journal

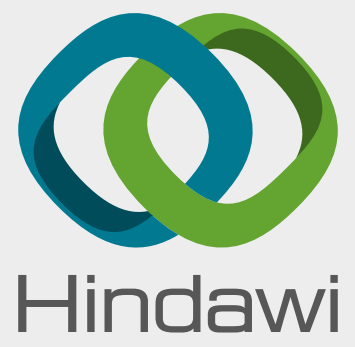

Submit your manuscripts at

www.hindawi.com
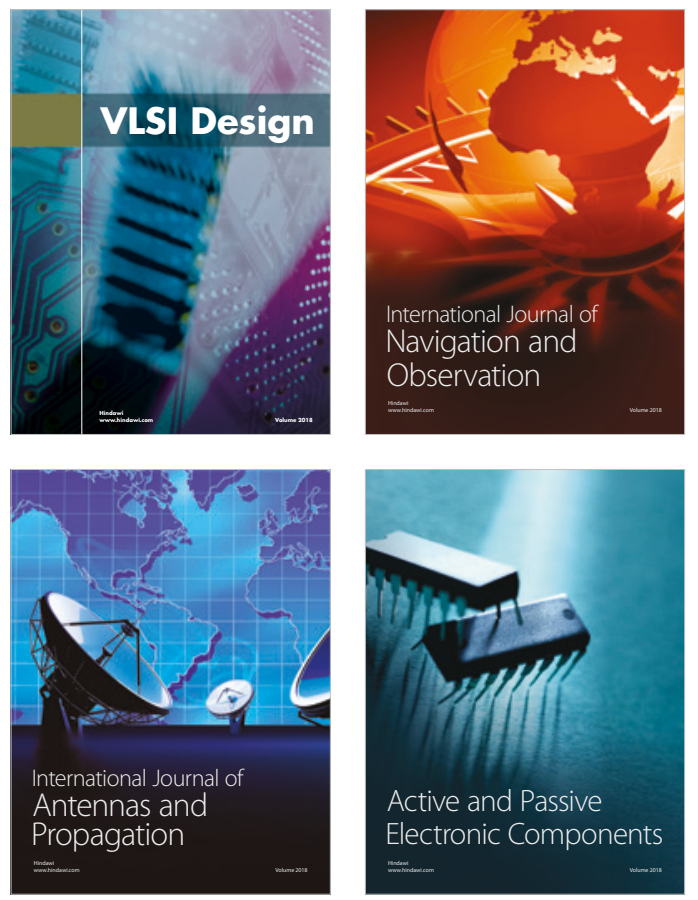
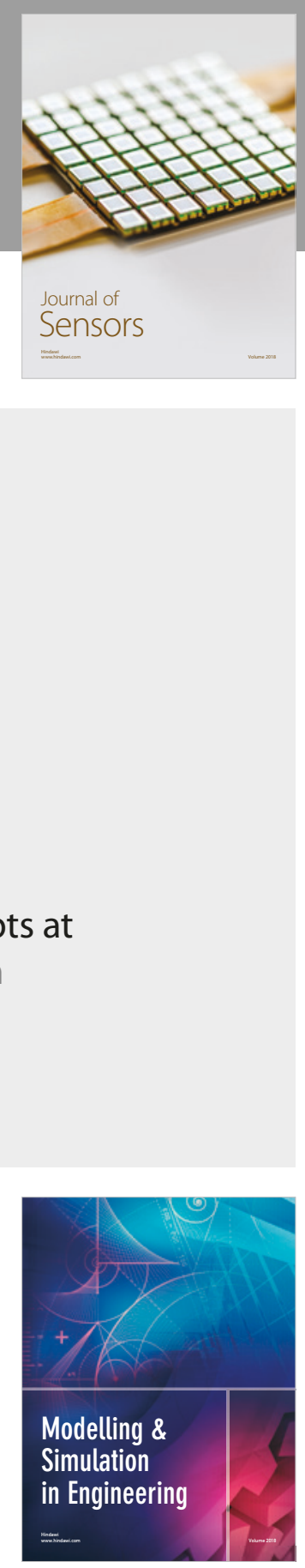

\section{Advances \\ Multimedia}
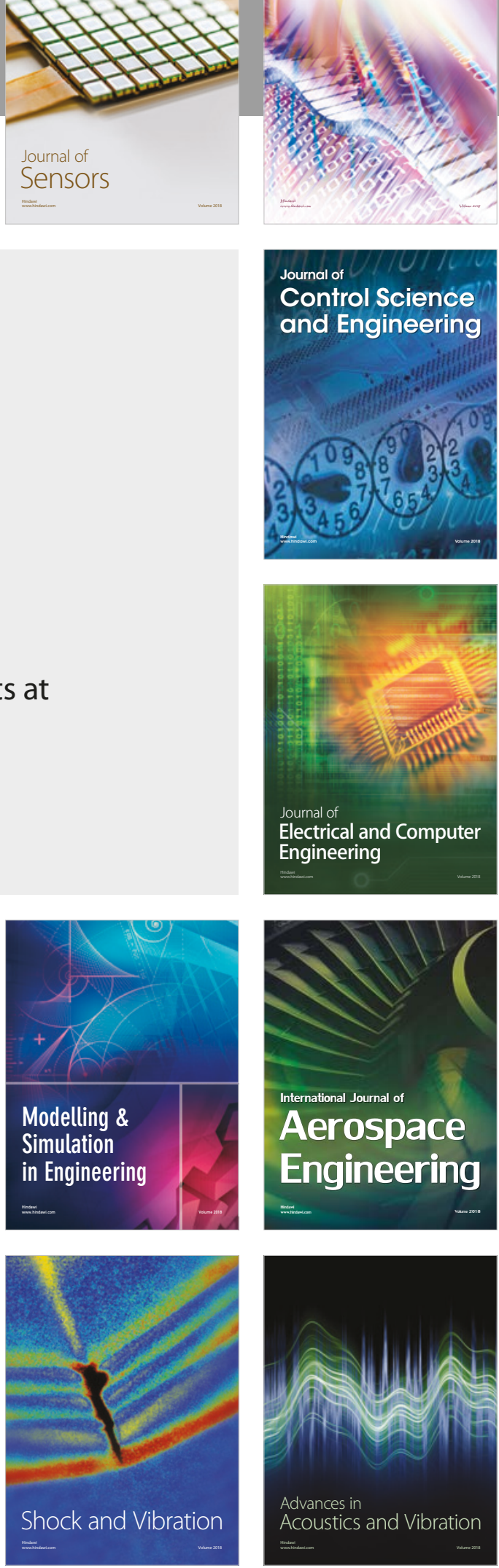